\title{
GENDER IDENTITY, ETHNIC IDENTITY, AND SELF-ESTEEM IN LATINO ADOLESCENT MALES
}

\author{
A Thesis \\ presented to \\ the Faculty of California Polytechnic State University, \\ San Luis Obispo
}

In Partial Fulfillment

of the Requirements for the Degree

Master of Science in Psychology

by

Miriam Asya Reder

March 2014 
(C) 2014

Miriam Asya Reder

ALL RIGHTS RESERVED 


\section{COMMITTEE MEMBERSHIP}

TITLE:

AUTHOR:

DATE SUBMITTED:

COMMITTEE CHAIR:

COMMITTEE MEMBER:

COMMITTEE MEMBER:
Gender Identity, Ethnic Identity, and Self-Esteem

in Latino Adolescent Males

Miriam Asya Reder

March 2014

Lisa Sweatt, Ph.D.

Professor of Psychology

Joseph Kelly Moreno, Ph.D

Professor of Psychology

Michael Selby, Ph.D.

Professor of Psychology 


\section{ABSTRACT}

Gender Identity, Ethnic Identity, and Self-Esteem in Latino Adolescent Males

\section{Miriam Asya Reder}

The relationship between gender identity and psychological adjustment has long been investigated, but it is only in the $21^{\text {st }}$ century that gender identity has been examined as a multifaceted construct. According to Egan and Perry (2001), there are five dimensions comprising a person's gender identity and they have demonstrated a significant relationship between these dimensions and youth's psychological adjustment. Three of their gender identity constructs are pertinent to this study: gender typicality, gender contentedness, and felt pressure. While subsequent studies have had similar significant results (Carver, Yunger, \& Perry, 2003; Yunger, Carver, \& Perry, 2004), one study found that felt pressure was not negatively correlated with adjustment in minority youth, including Latinos, as it was with majority White samples from the previous studies (Corby, Hodges, \& Perry, 2007).

Minority youth face more pressure to conform to gender stereotypes (Corby et al., 2007) and Latinos in particular face more rigid gender stereotypes than European American cultures (Corona, Gonzalez, Cohen, Edwards, \& Edmonds, 2009). While having a strong ethnic identity has been significantly correlated with self-esteem in Latinos (Umaña-Taylor, 2004), the relationship between ethnic identity, gender identity, and self-esteem in Latino youth have been underrepresented in the literature (Mora, 2012). Since Latino male youth in particular are at-risk for low-self esteem (Twenge \& Crocker, 2000) and self-esteem is a protective factor in adolescents (Hosogi, Okada, Fujii, Noguchi, \& Watanabe, 2012), it is important to pinpoint variables that are related to high self-esteem.

The purpose of this study is to explore the relationship between ethnic identity, gender identity, and self-esteem in an understudied population in the literature. The sample consisted of 55 males, aged 10-14, who are members of a school-based intervention program for boys at-risk of gang membership. The majority of boys were of Latino heritage. It was hypothesized that gender typicality and gender contentedness would be significantly correlated with self-esteem, and that ethnic identity would mediate the relationship between felt pressure and self-esteem. Statistical analysis yielded partial support for the hypothesis. Implications and future directions are discussed.

Keywords: Latino, at-risk youth, gender identity, ethnic identity, self-esteem, gangs 


\section{ACKNOWLEDGMENTS}

I would like to first and foremost thank my Thesis Chair, Dr. Lisa Sweatt, for your endless supply of encouragement, advocacy, patience, revisions, and for the constant reminder to always return to the literature. You are a wonderful supporter and sounding board, and I am grateful for your leadership and guidance during this process.

I would also like to thank Dr. Kelly Moreno for your edits, our discussions on research and the future, and advising me to keep my eye on the prize. Dr. Michael Selby, thank you for always keeping your office door open, for teaching me the importance of validity and reliability, and for telling me to not reinvent the wheel. I would also like to thank Dr. Gary Laver, who is so adept at explaining statistics to a beginner, for letting me take up several of your afternoons.

Thank you to the leaders of Youth In Action (YIA), Pedro Arroyo and Leticia Zendejas, who helped coordinate the assessment periods and shared your class time. I could not have done this project without your help. Also, thank you to the YIA students for your willingness to participate in this study and to answer the questions so honestly.

To my mom and dad, your support and belief in my abilities to accomplish this project meant the world to me. Thank you for your edits, discussions, reminding me to breathe and run, and for creating a wonderful space for me to relax and to feel loved.

Thank you to family friends and relatives for inquiring about my project and commiserating on your own thesis/dissertation experience-it is a wonderful thing to not feel alone! To my friends across the country and in school, who are a drive, email, card or phone call away, you gave me fun, laughter and shoulders to lean on. Thank you for believing in me. 


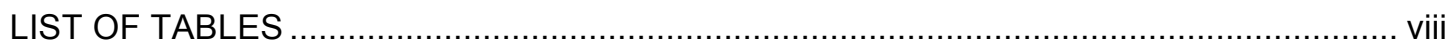

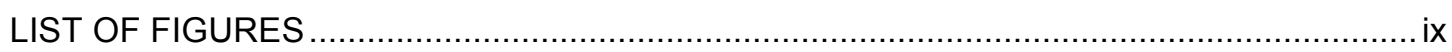

CHAPTER

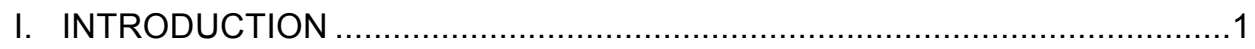

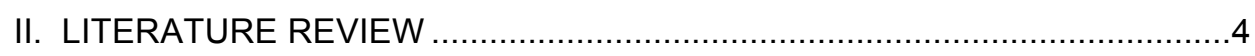

Introduction to Literature Review .....................................................

Introduction to Gender ........................................................

Historical Overview of Gender Development Theories..........................5

Measuring Gender Role Orientation .................................................

Sex Role Orientation Models in the $20^{\text {th }}$ Century...............................

Gender Identity in the $21^{\text {st }}$ Century: A Multidimensional Analysis .........15

Cultural Considerations: Latino Adolescent Males ............................18

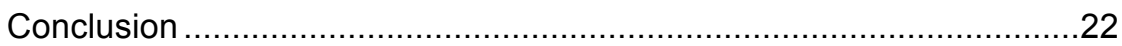

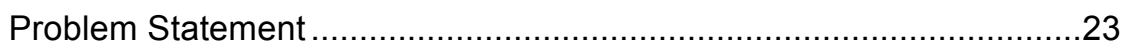

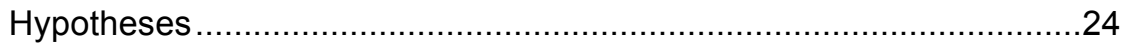

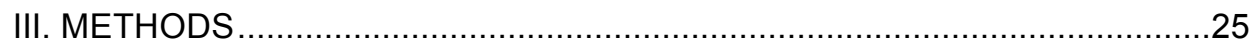

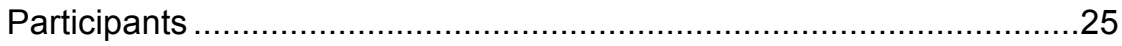

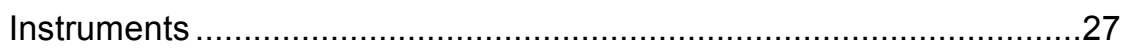

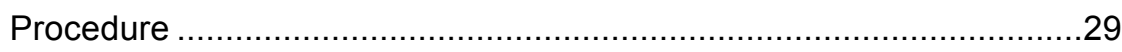

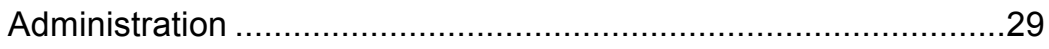

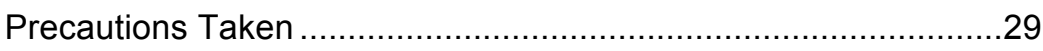

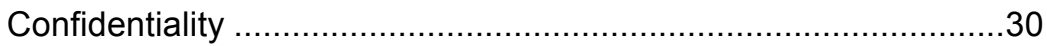

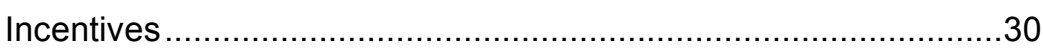

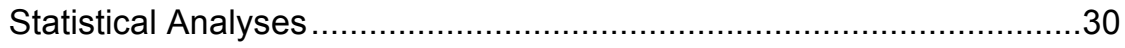

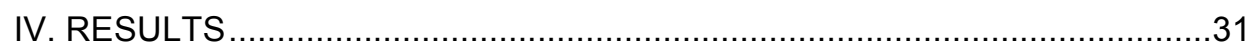

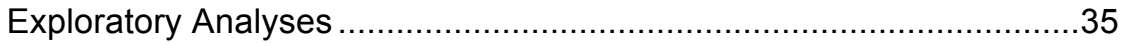

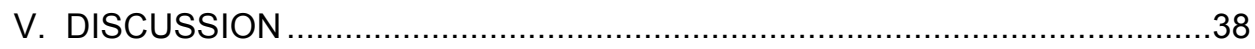

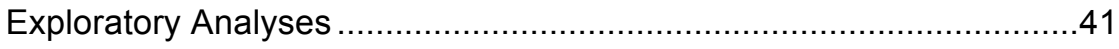




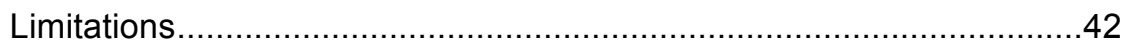

Implications of Study and Future Directions ....................................43

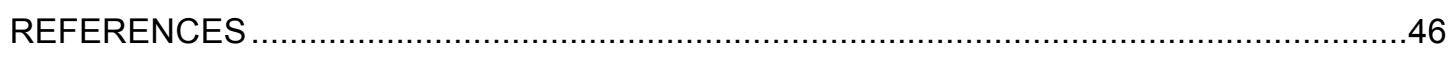

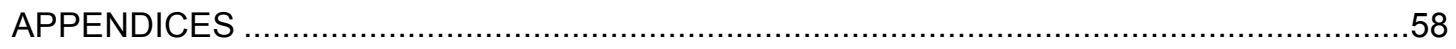

A. Cover Page of Participant Questionnaire Packet ........................................58

B. Felt Pressure Scale (Egan \& Perry, 2001) ...............................................59

C. Gender Contentedness and Gender Typicality Scales

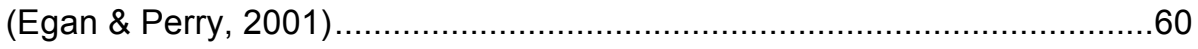

D. Rosenberg Self-Esteem Scale (Rosenberg, 1989) ..................................63

E. Ethnic Identity Teen Conflict Survey

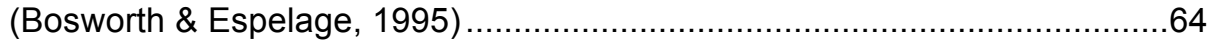

F. Informed Consent (English and Spanish) ..........................................65 


\section{LIST OF TABLES}

Table

Page

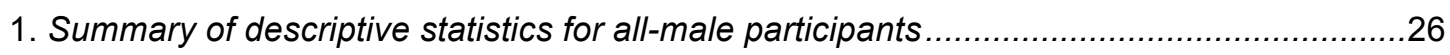

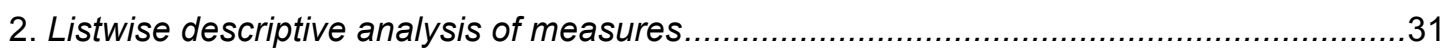

3. Correlation Coefficient Matrix for Variables ......................................................................

4. Summary of Regression Analysis for Variables Predicting

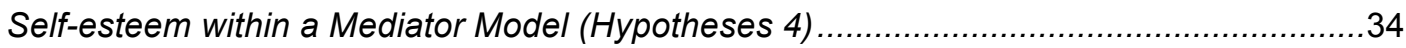

5. Summary of Regression Analysis for Variables Predicting

Self-Esteem of Regression Analysis for Variables Prediction 


\section{LIST OF FIGURES}

Figure

Page

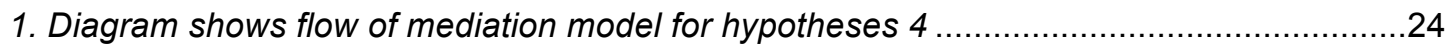

2. Diagram shows flow of mediation model for exploratory analyses....................................35 


\section{CHAPTER ONE}

\section{Introduction}

For much of the $20^{\text {th }}$ century, gender identity was typically examined through one lens: how sex role orientation (a person self-identified as having masculine or feminine personality traits) was related to psychological adjustment (Zosuls, Miller, Ruble, Martin, \& Fabes, 2011). Research has shown that a masculine gender role orientation in both males and females is a significant predictor of adjustment, specifically self-esteem (Whitley, 1983).

At the beginning of the $21^{\text {st }}$ century, researchers began calling for a multidimensional approach to gender identity, stating that sex-typed personality characteristics cannot solely account for a person's gender identity across varying domains, such as relationship styles and activity preferences (Perry \& Pauletti, 2011). Egan and Perry (2001) developed a multidimensional framework to examine gender identity in children and adolescents. The framework consisted of five constructs, including: membership knowledge (knowledge of one's own gender); gender typicality (perceived similarity to same sex individuals); felt pressure (experiencing pressure from parents, peers and the self to conform to gender stereotypes);

gender contentedness (satisfaction with one's gender assignment); and intergroup bias (believing one's gender is superior to the other). The researchers investigated these constructs in relationship to psychosocial adjustment (i.e. global self-worth and perceived social competence) in children. Pertinent to this study are gender typicality, gender contentedness and felt pressure.

In primarily Caucasian samples, gender typicality and gender contentedness had positive effects on psychological adjustment, while felt pressure had negative effects (Carver, Yunger, \& Perry, 2003; Egan \& Perry, 2001; Yunger, Carver, \& Perry, 2004). In a study examining gender identity and psychological adjustment among White, Black and Hispanic preadolescents (Corby, Hodges, \& Perry, 2007), feeling typical of one's gender was positively related to adjustment in White and Hispanic students and gender contentedness was positively related to adjustment in Black students. Felt pressure was negatively related to adjustment in White 
students, was not significantly related to adjustment for Black students, and was actually related to decreased internalizing problems (a construct of adjustment) in Hispanic students (a positive correlation). Additionally, both Black and Hispanic students reported feeling more pressure to conform to gender stereotypes than Caucasian students. These findings highlight two things. First, that gender identity and its relationship to adjustment may vary across different ethnicities and cultural contexts. Second, there is a clear discrepancy in how felt pressure relates to adjustment in White youth (negatively) and in Black and Hispanic youth (not at all in the former, somewhat positively for males in the latter), who incidentally experience more felt pressure than White youth.

Research has demonstrated a significant positive relationship between having a strong ethnic identity and high self-esteem (Umaña-Taylor, 2004), but there is limited research on how this relationship interacts with gender identity in Latino male youth (Mora, 2012). Understanding what facets of identity have a positive effect on self-esteem in this population is of particular importance because research shows that Latino male youth are at-risk for negative health outcomes (Corona, Gonzalez, Cohen, Edwards, \& Edmonds, 2009), including low self-esteem (Twenge \& Crocker, 2000). Self-esteem, one of the most widely used measurements of psychological adjustment in gender identity research (Whitley, 1983), is an evidenced protector from mental distress in children and adolescents (Hosogi, Okada, Fujii, Noguchi, \& Watanabe, 2012). Therefore, it is of clinical and empirical importance to investigate the relationship between gender identity, ethnic identity, and self-esteem in an understudied and at-risk population.

This study's sample consisted of 57 pre-adolescent and adolescent students who were members of Youth In Action, a yearlong school-based intervention program for males at-risk of gang association and/or membership. The students' ages ranged from 10-14 and were in the fifth through eighth grades. The majority of students were of Latino heritage. It was hypothesized that gender typicality, gender contentedness, and having a strong ethnic identity would be positively related to self-esteem, and that ethnic identity would mediate the relationship between felt pressure and self-esteem. Pearson correlations coefficients and an analysis of mediation were 
conducted. Results partially supported the above hypotheses. Exploratory analyses, limitations, future directions and implications of this study as applied to the clinical and empirical psychology professions are discussed. 


\section{CHAPTER TWO}

\section{Literature Review}

Introduction to Literature Review

This literature review examines the theories and empirical evidence related to concepts of gender role identity and self-esteem, as well as cultural considerations within the Latino population. An introduction to gender is followed by a brief historical overview of gender role development theories and then discusses how gender role orientation and self-esteem have been typically measured in the $20^{\text {th }}$ century. How researchers currently conceptualize and measure this relationship in the $21^{\text {st }}$ century is also discussed. Issues of concern found to be prevalent within the Latino population are highlighted, as are Latino gender roles and the relationship between ethnicity and self-esteem. A summation of the literature and the list of hypotheses conclude the review.

Introduction to Gender

The term gender refers to "social, cultural and psychological aspects linked to males and females through particular social contexts." (Lindsey, 1997, p. 3). Fagot and Leinbach (1993) point out that no single child is exempt from living in a gender-free world, highlighting how pink and blue newborn blankets are used to differentiate gender and how children's toys are typically gender-specific. In fact, research shows that by the age of three, children tend to choose and play with toys that are stereotyped in their culture as gender appropriate, known as sex-stereotyped toys (O’Brien \& Huston, 1985).

Fagot, Leinbach, and O'Boyle (1992) examined gender stereotypes in two and three year old children by having the participants complete a gender labeling test (identifying if a person is a boy or girl) and a gender-stereotyping test. This test consisted of some of the most sexstereotyped items in American society including conventional figurative sex-typed items based on gender stereotypical occupations (fire hat verses apron) and metaphorical sex-typed items (angry-faced bear verses butterfly). The children had to decide which items belonged to the 
mother and daughter or father and son. Results showed that even children under three years old could make sex-typed associations with figurative and metaphorical items and that those who comprehended gender labels were also more aware of gender-stereotyped associations. A separate study found that categorizing people based on gender could emerge when a child is just two years old and that gender category knowledge is related to developing gender-typed behavior, which are behaviors considered culturally appropriate for each gender to perform (Zosuls, Ruble, Tamis-LeMonda, Shrout, Bornstein, \& Greulich, 2009). Understanding gender is usually the first collective social identity learned by children (Zosuls et al., 2009) and even in the $21^{\text {st }}$ century, butterflies for girls and angry bears for boys become sex-typed items at a very young age.

\section{Historical Overview of Gender Role Development Theories}

Gender identity is defined as a person's sense of him self or her self as being male or female and a major component of gender identity is gender roles, which refers to society associating certain behaviors and attitudes with males and females (D'Andrea \& Daniels, 2001). Mussen (1969) describes the power that gender roles play in a person's development: "No other social role directs more of his overt behavior, emotional reactions, cognitive functioning, covert attitudes and general psychological and social adjustment" (p. 707). How the development of sex roles occurs has been explored since Freud's time and has historical roots in psychoanalytic, social learning and cognitive-development theories.

The original psychoanalytic theory, identification as posited by Freud, states that sex role development is related to a child's identification with their same-sexed parent (Weitzman, 1979). For instance, a boy between the ages of three and six who is experiencing the Oedipus complex develops an attraction for his mother and views his father in a hostile manner because he is interfering with receiving his mother's adoration (Mussen, 1969). When the boy eventually becomes fearful that his father will retaliate by means of castration due to his hostility and wanting of the mother, the boy will instead identify with the father rather than seeing him as a competitor. 
The resolution of the Oedipus complex enables the boy to adopt the characteristics of his father and thus receive his mother's love vicariously. If he is the father, then he has the mother's love.

Social learning theory contrasts with psychoanalytic theory in how it considers gender socialization in the context of environmental influences rather than internal processes or motivations and biological effects. Social learning theory proposes that adults will model appropriate gender behavior and children will be rewarded for properly imitating the behaviors and punished for sex-inappropriate behaviors (Lindsey, 1997). Stereotypic peer play, genderrelated grooming, and dress are examples of behaviors that are modeled and reinforced for children in their respective society. Children begin to comprehend that there is differential reinforcement for performing girl and boy behaviors and they will learn to act in a way that gets them a gender label associated with the rewards. This recognition, that boys and girls act differently and that there are two different gender roles, is the formation of one's gender identity.

Lawrence Kohlberg's view of gender identity veers from social learning theory in that gender identity is obtained only when a child understands what gender he or she is and will remain that way, which occurs between ages five and seven (Lindsey, 1997). The foundation of Kohlberg's cognitive development theory is that a child's ability to comprehend the world is connected to the child's cognitive development, and this understanding of the world is organized through the self. When the child's cognitive development enables him or her to understand their own gender category, the child will then behave in ways that are congruent with this identity and their own sense of self by actively looking at models for such behaviors (Kohlberg, 1969). The individual has an emotional attachment to his or her own gender identity and this identity is a crucial component of the self (Lindsey, 1997).

Another view of gender role development is Sandra Bem's gender schema theory (Bem, 1981). A schema is a cognitive structure that helps an individual to organize their understanding of the world (Lindsey, 1997). Children first have to have a cognitive awareness of what gender actually is and then they learn appropriate cultural gender norms. These gender norms are integrated into their self-concept and become the basis for organizing all other information. Bem 
(1981) believes that sex typing — masculine and feminine traits that are deemed culturally appropriate for males and females by society-is actually a result from this gender schema. "The child learns to apply this same schematic selectivity to the self, to choose from among the many possible dimensions of human personality only that subset defined as applicable to his or her own sex...Simultaneously, the child also learns to evaluate his or her adequacy as a person in terms of the gender schema" (p. 355). The child's self-esteem becomes tied up with their gender schema, as he or she attempts to behave in ways that are congruent with masculine and feminine traits.

\section{Measuring Gender Role Orientation}

The concept of gender role identity received a lot of attention during the $20^{\text {th }}$ century from psychology theorists and researchers (Zosuls, Miller, Ruble, Martin, \& Fabes, 2011). In particular, the relationship between sex typing and psychological adjustment was often investigated. Sex typed individuals refers to men and women who consistently maintain behaviors and attitudes perceived to be masculine or feminine in their society (Smoak, 2008). Much of the literature has conceptualized masculinity and femininity in a traits-based framework, and the male and female's possession of these traits have comprised their sex role orientation (Smoak, 2008). Agency or instrumentality traits are considered masculine, including assertiveness, taking control and selfprotection. Traits that demonstrate communal tendencies, such as liking group interactions and being other-oriented, are considered feminine and are called expressive characteristics. Instrumental and expressive traits have been used to measure sex role orientations and sextyping. According to Fernandez and Coello (2010), the two most popular sex-typing instruments

are the Personal Attributes Questionnaire (PAQ; Spence, Helmreich \& Stapp, 1974) and the Bem Sex Role Inventory (BSRI; Bem, 1974).

The $P A Q$ measures if an adult male or female's sex role orientation is masculine (high in masculine traits), feminine (high in feminine traits), androgynous (high in both feminine and masculine traits) and undifferentiated (low in both feminine and masculine traits). To develop this scale, researchers provided a list of personality traits to college students and asked them to judge 
which characteristics were ideally found in men and women, but were thought to be more typical of a specific gender (Kelly \& Worell, 1977). Independent, outgoing, ambitious and competitive attributes were considered more typical in males. Attributes considered more typical in females included being emotional, gentle, kind and understanding. The $P A Q$ also has a third scale that is comprised of traits deemed socially desirable for male or females, meaning those specific traits were considered ideal for only one sex and not the other (Hall \& Halberstadt, 1980).

Another widely used scale, the Bem Sex Role Inventory (Bem, 1974), also measures masculine, feminine, androgynous, and undifferentiated sex role orientations in adult men and women. Bem and several other students created a 200 -item list of positive personality characteristics that could be attributed to a masculine or feminine category and a 200 -item list that had gender-neutral positive and negative characteristics (Bem, 1974). One hundred male and female college students judged each item as being representative or non-representative of "socially desirable [masculine or feminine] characteristics in American society" (Choi \& Fuqua, 2003, p. 873). Twenty desirable items were then chosen for each category-masculine, feminine and neutral-to create a 60-item questionnaire. The masculine category was constructed to measure socially desirable masculine traits built around a central theme of instrumental orientation, or a "cognitive focus on getting the job done" (Choi \& Fuqua, 2003, p. 874). The feminine category was constructed to measure socially desirable feminine traits focused on the theme of expressive orientation, or "affective concern for the welfare of others" (Choi \& Fuqua, 2003, p. 874). The Children's Sex Role Inventory (CSRl; Boldizar, 1991), an instrument that is considered to be the children's conceptual equivalent to the $B S R I$, is also available to help researchers look at changes occurring in androgyny and sex typing from middle childhood through adulthood in addition to measuring sex typing among children.

The $B S R /$ has been employed over 1,000 times in research studies since its development in 1974, making it one of the most widely used instruments in research examining gender role orientation (Beere, 1990). Given the measure's frequent use over several decades and societal changes that have occurred in America since 1974, such as more women entering the workforce 
(Auster \& Ohm, 2000), the validity of the BSRI as measuring gender role orientation in contemporary society has come into question, though with conflicting results. One study concluded that there is a smaller magnitude of difference between characteristics considered desirable for males and females than there had been in the original sample, implying that this study's subjects had weaker gender role stereotyping than in Bem's 1974 subjects (Holt \& Ellis, 1998). This suggests that the BSRl's validity could actually be decreasing over the years. However, the amount of change in this gender role stereotyping only suggests that the validity may be weaker and is not actually enough to currently invalidate the BSRI.

A separate study suggested that there is a lack of masculinity and femininity theoretical dimensions in the original creation of Bem's femininity and masculinity scales, which negatively affect the BSRl's construct validity (Choi \& Fuqua, 2003). The authors came to this conclusion after compiling a summary report of 23 past $B S R I$ validation studies. However, they were careful to note that the majority of these validation studies had a homogenous sample ( 16 of the 23 studies had college student participants) and that "there are probably many good reasons to believe that sex role orientation may require different structural definitions as one moves from one group to another" (p. 883). Fernandez and Coello (2010) echo this study's view that the masculinity/instrumentality and femininity/expressiveness definitions are too ambiguous. The authors add that a multidimensional perspective of gender identity needs to be given more emphasis, a perspective that is also suggested by others (Zosuls, Miller, Ruble, Martin \& Fabes, 2011).

\section{Sex Role Orientation Models in the $20^{\text {th }}$ Century}

Three competing models dominated the sex role orientation and psychological adjustment research during the $20^{\text {th }}$ century, including the traditional congruence model, the androgyny model, and the masculinity model (Cate \& Sugawara, 1986), the latter two entering the gender role identity investigations in the 1970 s and 1980s. The traditional congruence model proposed that one's sex role needed to be congruent with one's gender to attain psychological adjustment in adulthood, where men are to be only masculine and females are to only be feminine (Lau, 1989). According to Massad (1981), many theorists believed that the primary task 
of adolescence was to establish a traditional sex-typed identity (e.g. Erikson, 1950; Kagan 1964; Kohlberg 1966; \& Mussen, 1969). "The acceptance of conventional sex roles and rejection of conflicting (i.e. cross-sex-typed) attitudes and behaviors was viewed as a pre-requisite to both psychological and social adjustment" (Massad, 1981, p. 1290). One's sex role orientation was defined as possessing traits appropriate for that gender and it was impossible to possess traits on the other end of the dimension (Reed-Sanders, Dodder \& Webster, 2001). Masculinity and femininity were construed on a bipolar continuum, where an individual could not be both masculine and feminine.

It was not until the 1970s that the necessity for traditional sex typing and for the masculine-feminine bipolar conceptual design was challenged. Massad (1981) discusses the change of view that occurred during the 1970's, as theorists emerged arguing that personality growth is limited by traditional sex typing. Masculinity and femininity were instead postulated to act as a kind of counterbalance within an individual. For instance, individuals with high levels of masculinity would promote insensitivity, domination, and inappropriate competitiveness because there would not be enough femininity to act as a counterbalance. Contrarily, individuals high in femininity and lacking masculinity would bring about too much passivity, incompetence, and dependence.

Block (1973) suggested that developing one's sexual identity is not linked to acquiring levels of masculinity or femininity, but instead is linked to a person secure enough with his or her gender that the person can embody masculine and/or feminine qualities regardless of gender. Hefner and Oleshansky (1975) and Pleck (1975) believed that an adolescent's task was not to develop a traditionally sex-typed role but to actually transcend such roles (Massad, 1981). The person's decision-making and thought process should be grounded upon the specific circumstances of the situation as well as the individual rather than acting in a way that conforms to traditional gender roles. Other theorists focused on the masculine-feminine bipolar construction, which led to the conceptualization of the androgyny model. Constantinople (1973) questioned whether masculinity and femininity could exist as two independent dimensions. 
Spence, Helmreich \& Stapp (1975) also argued that masculinity and femininity were not inherently incongruous (Silvern \& Ryan, 1979).

This argument was strongly supported by Sandra Bem, who in 1974 introduced the androgyny model into the gender role arena. Bem (1974) stated that viewing masculinity and femininity on just one continuum excluded the hypothesis that men and women could possess both characteristics, regardless of gender. A man high in masculinity could also be high in femininity and a woman high in femininity could also be high masculinity. She called these individuals androgynous and posited that individuals could be instrumental and expressive depending on what behaviors would be most appropriate in any given situation. Bem (1974) wondered if sex-typed individuals were very limited in their behaviors regardless of what situation they are in because they would not want to engage in behaviors they think are inappropriate or undesirable for their gender. An androgynous person would thus have more behaviors available to them while highly sex-typed people would be motivated to maintain their internalized gender role standards (Silvern \& Ryan, 1979).

The idea that an androgynous sex role orientation promotes optimal mental health soon garnered attention and support. For instance, Gilbert (1981) proposed that masculine and feminine characteristics limited to only one sex places restraints on what personality traits, activities and roles are considered gender appropriate. She states that viewing women as the dependent gender unfairly implies that they lack strong leadership abilities and therefore should not have influential positions in society. Contrarily, viewing men as the independent gender implies that their nurturing and expressive capacities will be limited.

Gilbert (1981) also points out that using the BSRI as an indicator of sex-typed personality traits means one is looking at "differences in degree, not kind" (31). She cautions that just because most men score higher on masculine, or instrumental traits, does not mean they completely lack feminine, or expressive traits, and vice-versa for women. Gilbert (1981) reports past studies demonstrating that androgynous males and females had the greatest social competence and self-esteem levels, with masculine, feminine and undifferentiated individuals 
following. Other studies demonstrated this pattern in that androgynous males and females reported the highest levels of self-esteem, followed by masculine, feminine and undifferentiated men and women (Bem, 1977; Gilbert, 1981; O’Connor, Mann \& Bardwick, 1978; Spence, Helmreich, \& Stapp, 1975).

A meta-analysis reported that self-esteem in particular has been the most common measurement of psychological adjustment and wellbeing in gender role identity research (Whitley, 1983). Self-esteem has been described as an "evaluative component of self-concept" (Pryor, 1994, p.48) and that it "is an attitude about the self and is related to personal beliefs about skills, social relationships, and future outcomes" (Heatherton \& Wyland, 2003). The first category of instruments measure global self-esteem, which examines a person's self-evaluation across different domains, such as personal skills, sexuality, and feeling of adequacy (Whitley, 1983). These instruments include the Self-Esteem Scale (RSES; 1989), and the Coopersmith SelfEsteem Inventory (1967). The second category of instruments measure social self-esteem, e.g. the Janis-Field Feeling of Inadequacy Scale (1959), which examines an individual's feeling of worth and adequacy in social interactions with others (Whitley, 1983). However, the Rosenberg Self-Esteem Scale remains the most commonly used instrument to measure self-esteem today (Huang \& Dong, 2011). The relationship between gender role identity and self-esteem received more attention once again, as a new gender identity model was proposed.

Though there was growing support for the theory that androgynous individuals have the highest levels of self-esteem, Kelly \& Worell (1977) pointed out how controversy still remained due to studies showing that masculine-typed individuals, and not just androgynous individuals, also had higher levels of self-esteem than feminine and undifferentiated-typed subjects (AlpertGillis \& Connell, 1989). The authors suggested that more research is needed on self-esteem and sex role orientation relationships because the masculine component of a male or female androgynous individual might be contributing to higher self-esteem levels. Kelly and Worell (1977) state that past research demonstrates how stereotyped masculine traits are rated as more socially desirable than feminine traits by college students (Rosenkrantz, Vobel, Bee, Broverman 
\& Broverman, 1968) and in mental health workers (Broverman, Broverman, Clarkson, Rosenkrantz, \& Vogel, 1970). The authors invoke the works of these studies to help build their foundation for questioning the androgyny model.

Kelly \& Worell's (1977) idea of looking at the role of masculinity and self-esteem in androgynous individuals helped to generate the masculinity model, which states that "...One's psychological well-being is seen to be a function of the extent to which one has a masculine sex role orientation, irrespective of one's gender" (Whitley, 1983, p. 766). Antill and Cunningham (1979) examined the function of masculinity in 237 male and female undergraduates who filled out three sex role instruments and two self-esteem measures. Results showed masculinity to have a significant positive correlation with self-esteem in both males and females, while the femininity correlations were slightly negative or nil. Additionally, the androgynous and masculinity groups never significantly differed from each other in self-esteem and the feminine and undifferentiated (the two lowest masculinity groups) never significantly differed from each other in self-esteem. This led the authors to conclude that masculinity serves as a major contributing factor to a male and female's level of self-esteem.

Lamke (1982) found similar results in adolescents, where masculine-typed traits in both genders were related to higher self-esteem levels. She also noted that though she used a selfesteem measure differing from some previous research she still achieved comparable findings, suggesting that the results are not scale specific and indicate a real relationship between selfesteem and masculinity in males and females. A separate investigation concluded, "Masculinity was a critical predictor of adjustment" (Silvern \& Ryan, 1979, p. 760). This was based on results showing that highly masculine groups (traditional men and androgynous men and women) were linked with the highest self-rated adjustment and that only masculinity had a significant main effect on the participants' adjustment.

The masculinity model was also supported by a meta-analysis that looked at the relationship between sex role orientation and self-esteem as a measure of psychological adjustment (Whitley, 1983). Results did not support the traditional congruent model and while 
masculinity, femininity and the two constructs' interaction all had positive relations with selfesteem, masculinity had the strongest. Whitley (1983) highlights an important methodological consideration from past studies. He says that the self-esteem measures of which "deal to a large extent with assertiveness in social situations" (p. 773) have the strongest relationship with masculinity. He suggests that social self-esteem instruments and masculinity scales could potentially be looking into similar constructs and overlapping. A separate meta-analysis examining how masculine and feminine traits have changed over time found that the changes in means of two sex role orientation measures $(B S R I$ and $P A Q)$ showed that men still do not endorse feminine-stereotyped characteristics and women still endorse masculine-stereotyped characteristics (Twenge, 1997).

According to Burnett, Anderson and Heppner (1995), reasons for masculinity's influence on self-esteem are three-fold. First, there is the controversy over the subscales' social desirability of gender role measures (Pedhazur and Tetenbaum, 1979), which posits that masculinity scale items were more socially desirable than femininity scale items. However, one study failed to find systematic difference in the social desirability on the PAQ and $B S R I$ instruments (Taylor \& Hall, 1982). Second, Burnett, Anderson and Heppner (1995) posit that there could be a masculinity bias in measures assessing types of wellbeing as mentioned in Whitley's (1983) meta-analysis. For instance, a study demonstrated that traditional wellbeing (focusing on depression, anxiety and self-esteem) had the strongest association with masculinity (Sharpe \& Heppner, 1991). However, affiliative wellbeing (e.g. intimacy and lacking conflict due to emotional restriction and competition) had the strongest association with femininity. These results suggest that different dimensions of wellbeing are more strongly associated with masculinity or femininity and that selfesteem —a traditional measure of wellbeing or psychological adjustment— is considered more strongly related to masculinity, biasing results. The third reason for the strong masculinity and self-esteem relationship is called the masculine supremacy effect (Cook, 1985; Yager \& Baker, 1979), which states that American culture gives positive social reinforcement to people who have a greater masculine sex role orientation and this in turn could enhance someone's self-esteem. 
Burnett, Anderson and Heppner (1995) argue that environmental influences have not been given the same attention as masculine and feminine characteristics have in gender role research. They examined if their undergraduate participants would feel social pressure ("environmental press") to exhibit more masculine traits rather than feminine ones, and how this relationship—as well as individual levels of masculinity and femininity — would interact with a person's self-esteem. Results yielded support for the masculinity model, where only individual masculinity was significantly correlated with males and females' self-esteem. Men and women reported feeling more pressure to demonstrate masculine traits over feminine traits, with their peers encouraging independence, achievement, and competition over sensitivity and satisfaction in relationships and emotional expressiveness. Lastly, the individuals low in masculinity were atrisk for lower self-esteem, especially women. These results led to the conclusion that "gender roles, which were previously studied in isolation from environmental influences, are embedded within a cultural context that can interact with one's personal traits" (p. 325).

\section{Gender Identity in the $21^{\text {st }}$ Century: A Multidimensional Analysis}

Researchers began to view gender identity as a concept encompassing more than just sex-typed characteristics, arguing for a multidimensional framework (Bailey, Hendrik \& Hendrik, 1987; DiDonato \& Berenbaum, 2011; Lam, McHale \& Updegraff, 2012). Egan and Perry (2001) argue that a multidimensional perspective is necessary because using personality sex-typed items (e.g. expressive/instrumental traits) to encompass a person's whole gender identity potentially leaves out an entire chunk of dimensions. One basis for this perspective is that people do not always exhibit the same gender-typed behaviors across situations (e.g. personality traits, activity preferences, or relationships styles; Perry \& Pauletti, 2011). Secondly, when people have to rate themselves on gender-typed attributes they may not realize that these attributes are in fact related to gender, which suggests that people's feelings about themselves in relation to gender categories may not be fully measured (Egan \& Perry, 2001). Lastly, assumptions have been made that it is the sex-typed characteristics that reflect perceived pressure to conform to one's 
gender role rather than other influences, such as temperamental inclinations (Egan \& Perry, 2001).

These arguments led Egan and Perry (2001) to create a gender identity multidimensional framework with five constructs. First is membership knowledge, or one's knowledge of belonging to a gender category (boy or girl). Second is gender typicality, where one perceives themselves as similar to same sex individuals. Third is gender contentedness, or how satisfied someone is with his or her gender assignment. Fourth is felt pressure, which is the degree to which one feels pressure from parents, peers and the self to conform to gender stereotypes. Fifth is intergroup bias, or believing that one's gender is superior to the other.

In Egan and Perry's (2001) study, gender typicality, gender contentedness, felt pressure and intergroup bias were explored in relation to adjustment in middle childhood with a sample of 182 children (68\% White), fourth through eighth grades. Results showed that the dimensions were related to psychosocial adjustment (global self-worth and self-perceived peer social competence; Harter, 1985). Specifically, high gender typicality was positively correlated with adjustment while high felt pressure was negatively correlated with adjustment in both males and females. This led the authors to conclude that children's adjustment is elevated when they view themselves as typical members of their gender, but feel they have room to engage in cross-sex opportunities when they want to. Results also showed that as children's levels of felt pressure increased, gender contentedness was increasingly predictive of global self-worth and selfperceived peer social competence. This suggests that low gender contentedness can be harmful to children's adjustment when they are experiencing high felt pressure, as they are not feeling happy with who they are pressured to be. Intergroup bias was harmful to children's relationships with peers, particularly with acceptance from boys.

Lastly, evidence showed that boys scored higher than girls did on gender typicality, gender contentedness, and felt pressure. The authors did not find this result surprising as past research has shown that boys are sex-typed more than girls and experience more pressure for sex typing than girls do. It is also worth noting that while felt pressure had negative effects on 
adjustment for both sexes, the negative effects were bigger for girls than for boys. Egan and Perry (2001) reasoned that male-typed characteristics, academic pursuits, and occupations tend to receive greater societal rewards than female equivalents do and since instrumental attributes help both sexes cope with challenges (Bussey \& Bandura, 1999), felt pressure may actually benefit males because society urges them to adopt culturally rewarding attributes.

The multidimensional analysis was used again with 206 third through eighth graders, 68\% identified as European American (Carver, Yunger \& Perry, 2003). Results showed that not only was feeling typical of the same sex significantly related to the children's psychological wellbeing, but those who felt atypical of same-sex members were viewed by peers as depressed, self-deprecating, victimized and anxious. This was especially strong for youth experiencing high felt pressure. High felt pressure also had a significant negative relation with self-esteem for girls, which the authors reasoned was due to girls avoiding "boy" activities that are associated with prestige and self-efficacy (Bussey \& Bandura, 1999). Gender contentedness was a "robust predictor of global self worth" (p. 106) and the authors add, "...a strong wish to engage in the activities [or] interpersonal roles... associated with the other sex apparently is uniquely depressing to children" (p. 106), especially if the children are experiencing high felt pressure. A separate two-year study using 171 third through seventh graders (59\% White) had similar conclusions, where low gender typicality was associated with low self-esteem (Yunger, Carver, \& Perry, 2004). Felt pressure was associated with internalizing difficulties, especially for children feeling atypical of their gender. Children who were unhappy with their gender had lower selfesteem and were not as accepted by their peers.

Corby, Hodges \& Perry (2007) examined gender typicality, gender contentedness and felt pressure and its relationship to adjustment (i.e. global self-worth, internalizing symptoms, and peer victimization) among White, Hispanic, and Black pre-adolescents. The results for White children remained similar to prior studies, with favorable adjustment associated with high gender typicality and gender contentedness, but low felt pressure (Carver et al., 2003; Egan \& Perry, 2001; Yunger et al., 2004). For Black children, only gender contentedness had any strong 
correlation with adjustment. For Hispanic children, gender typicality was associated with good adjustment as much as it was for White children. However, gender contentedness in Hispanic girls was associated with higher internalizing problems and felt pressure in Hispanic boys was associated with lower internalizing problems. This suggests that felt pressure may effect Hispanic boys in a more positive way than it does for White boys. Additionally, both Hispanic and Black children had significantly more felt pressure than White children.

The authors proposed the following reasons for these findings. Black and Hispanic children are part of a more collectivist culture, which lends itself to more pressure to conform and studies have shown minorities put more pressure on themselves to follow a group norm. Also, felt pressure and typicality showed no effects on adjustment in Black children and this may be because they are dealing with a racial minority identity that may be overshadowing other identity influences. Lastly, Hispanic girls with higher internalizing problems also had higher gender contentedness and this may be due to them living in a more patriarchal culture which stresses the role of masculinity.

The authors assert that this particular multidimensional framework needs to be explored more in order to comprehend the reasons for their results. They add, "No assessments were made on cultural variables that might permit inferences about cultural influence" (p. 265). Keeping this in mind, it seems that using the multidimensional and adjustment perspective while examining cultural variables' effects on the results, such as a strong ethnic identity, is a fruitful next step in this multidimensional analysis.

\section{Cultural Considerations: Latino Adolescent Males}

Between 2000 and 2010, over half the growth of the American population was due to a 15.2 million rise within the Latino population (U.S. Census Bureau Brief, 2011). The Latino population residing in America during 2010 was estimated to be over 50 million people. A Latino is defined as, "...A person of Cuban, Mexican, Puerto Rican, South or Central American, or other Spanish culture or origin regardless of race" (U.S. Census Bureau Brief, 2011, p. 2). 
With this population increase has come more research on Latino adolescents and specific stressors they may be facing. A qualitative study conducted on U.S. Latinos reported that over $75 \%$ of the participants expressed concern with youth drug and/or alcohol use and behavioral problems at school or home (Corona et al., 2009). Research shows that U.S. Latino youth are at higher risk for experiencing negative health outcomes, including delinquency, violence, school drop- outs and alcohol and drug use (Corona et al., 2009). Another study found that when comparing U.S. Hispanic and U.S. non-Hispanic White high school students, Latino students participated in a higher amount of risk-taking behaviors (Brindis, Wolfe, McCarter, Ball, \& Starbuck-Morales, 1995). This same study also concluded that Latino boys had a significantly higher rate of reporting risk behaviors than Latina girls. Associations have also been found between Latino males and increased odds of fighting, and poverty has been associated with depression among Latinos as well (Shetgiri, 2010). Additionally, a meta-analysis comparing selfesteem and race found that in comparison to Whites, minority males had lower self-esteem than the minority females (Twenge \& Crocker, 2000).

Low self-esteem has been found to have a detrimental effect on individuals, including a more negative view of the world and putting individuals more at-risk for depression, loneliness, alienation and shyness (Heatherton \& Wyland, 2003). In adolescents, low self-esteem has been associated with self-harm and was found, along with negative emotionality and self-blame, to predict future self-harm during the next year (Phillips, Spears, Montgomery, Millings, Sayal, \& Stallard, 2013). Research has demonstrated how high self-esteem can help individuals effectively handle challenges (Heatherton \& Wyland, 2003) and can serve as protection from mental distress in children and adolescents (Hosogi et al, 2012; World Health Organization, 2000). Pinpointing variables that enhance self-esteem in adolescents, especially in Latino male youth who are evidenced to be experiencing a myriad of behavioral and health challenges, is of particular salience.

Latino gender roles are well defined, and according to the 2006 Latino National Survey, Latinos are less liberal in their attitudes towards these roles than other groups in the United 
States (Falconier, 2013; Parra-Cardona, Cordova, Holtrop, Villarruel, \& Wieling, 2008). Traditional Latino males have been described as the dominant gender and are considered to be at the top of the family hierarchy (Santiago-Rivera, Arredondo \& Gallardo-Cooper, 2002). They are said to possess a drive to prove their sexual virility, control, and power over other men and women (Chant \& Craske, 2003). This group of characteristics is commonly associated with the word machismo, which connotes a man's masculinity in Latino culture (Ingoldsby, 1991).

The concept of machismo is embedded in Latin American history, with different theories as to its origination (Chant \& Craske, 2003). One view states that the Spanish conquerors, who defeated the indigenous men and sexually assaulted their women, ignited an extremely aggressive and masculine response from the natives in order to offset their feelings of powerlessness and humiliation. Another view is that the Spanish culture brought machismo into the New World and this led to the Church and State dictating a patriarchal culture with subservient and chaste women. Whatever the origination, it is clear that machismo is deeply rooted in Latino culture and ascertaining one's machismo is still relevant in today's Latin American society. For instance, Chant and Craske (2003) discuss how male-only saloons (cantinas) in Costa Rica exist for men to drink and socialize without the "domesticating influences of women and children" (p. 16), and how bullrings also provide a space for men to prove their masculinity to other men and women.

The perceived rigidity of Latino gender roles, with men representing a dominant, independent, aggressive and heavy drinker persona and women representing a chaste, submissive and dependent persona (Comas-Diaz, 1987; Raffaelli \& Ontai, 2004), has drawn criticism from some Latino psychologists (Santiago-Rivera, Arredondo \& Gallardo-Cooper, 2002). Machismo is associated with some negative attributes, such as sexual aggression and heavy drinking, and these associations have sometimes overshadowed the positives, including a Latino man's loyalty, honor, and sense of responsibility to protect and provide for his family and fellow community (Morales, 1996, p. 274). Falicov (1998) states that a good Latino man, un caballero (a gentleman), aims to satisfy other women and is especially devoted to women within his family, 
particularly his mother. Falicov says, "Machismo requires men to be family oriented, brave, hard working, proud, and interested in the welfare and honor of their loved ones. Viewed through this lens, machismo can be a bridge rather than an obstacle to engagement in therapy" (p. 198), referring to the traditional belief that Latino men do not want to ask for help. Recent Latino research has examined the stereotype that Latino men are disengaged, abusive, hard drinkers, and unreliable husbands (Chant \& Craske, 2003). Studies show that men residing in a lowincome Mexico City community play and hold their children, forge deep bonds with their sons, and view fatherhood as a forever obligation (Chant \& Craske, 2003; Gutmann, 1996).

This more positive view of machismo has brought forth a two-dimensional model of conceptualizing Latino masculinity, as seen in an investigation looking to develop a machismo scale (focused on hypermasculinity) and a caballerismo scale (focused on emotional connectedness; Arciniega, Anderson, Tovar-Blank \& Tracey, 2008). Using these two independent constructs in two separate studies with Mexican American men, the authors found that traditional machismo was related to wishful thinking (as a coping strategy) and higher levels of antisocial behavior, aggression, and alexithymia ("the degree to which one is not aware of affect," p. 30). Caballerismo was positively associated with problem solving, ethnic identity, and affiliation. The authors stress that men can possess traits from both scales and that it is important to view Latino masculinity in more than one way. This parallels Egan and Perry's (2001) argument for looking at gender identity through a multidimensional lens.

Mora (2012) argues that masculinity as both a social and cultural identity construct in Latino boys is not well studied in America and that literature is lacking in how ethnicity influences masculine identities. Ethnicity is defined as "cultural traditions and values that are transmitted across generations" (Toomey \& Umaña-Taylor, 2012, p. 8) and ethnic identity is defined as "how individuals interpret and understand their ethnicity and the degree to which they have a sense of attachment to their ethnic group" (p. 8; Phinney, 1996). Research shows existing links between ethnic identity and self-esteem. One study with monoracial and biracial adolescents found a significant, positive relationship between ethnic identity and self-esteem (Bracey, Bamaca \& 
Umaña-Taylor, 2004). Other studies have had similar results, including one where ethnic identity significantly predicted self-esteem among all ethnic groups, including Latinos (Phinney, Cantu \& Kurtz, 1997). Another found that ethnic identity and self-esteem had a significant positive relationship among Mexican-origin adolescents in all school settings (mostly Latino, mostly nonLatino and balanced populated schools; Umaña-Taylor, 2004).

Understanding how ethnic identity may influence the multidimensional gender identity relationship (gender typicality, felt pressure and gender contentedness) with self-esteem among males can be a fruitful next step in Latino research. Looking at this relationship among Latino male adolescents is of particular importance. As Falicov (1998) notes, more egalitarian views are entering the Latino landscape and there are shifting gender role dynamics in migrated families. This is igniting generational conflict between parents and children regarding gender roles, curfews, sex, drinking, dress and dating. Mora (2012) concludes that, "pubescence is a social process...that is interactional, collective, embodied, and situated in classed, gendered and ethnoracialized contexts" (p. 455).

\section{Conclusion}

Research has shown that minority males have lower self-esteem than minority females (Twenge \& Crocker, 2000) and that Latino boys have a significantly higher rate of risk-taking behaviors than Latina girls (Brindis et al., 1995). It seems that Latino male youth are a particularly vulnerable population and research is needed to understand what parts of their identity contribute to protective factors, such as self-esteem.

Pinpointing variables that can enhance a person's psychological adjustment, particularly self-esteem, is of clinical importance because it is well documented that having low self-esteem is associated with mental health problems, including depression (Orth \& Robins, 2013). According to Piña-Watson, Ojeda, Castellon, and Dornhecker (2013), there is a significant relationship between self-esteem and lifetime trajectories of relationship and job satisfaction, school dropouts, and physical health issues. 
Gender identity is a documented contributor to self-esteem in youth, specifically when examining masculine traits, being content with one's gender, and feeling typical of one's gender (Carver et al., 2003; Egan \& Perry, 2001; Whitley, 1983; Yunger et al., 2004). Felt pressure, another facet of gender identity, has had mixed significant results with adjustment. While felt pressure was significantly negatively correlated with adjustment in White youth, it was not negatively significant among Black and Hispanic youth (Corby et al., 2007). In fact, high felt pressure was related to lower internalizing problems in Hispanic boys. This is an especially interesting finding because research shows that boys experience more pressure than girls to conform to gender stereotypes and that minority youth experience more pressure than White youth to conform (Corby et al., 2007; Egan \& Perry, 2001).

Ethnic identity has been significantly correlated with self-esteem in several studies with participants of Latino heritage (Bracey et al., 2004; Phinney et al., 1997; Umaña-Taylor, 2004). Given the evidenced link between ethnic identity and self-esteem, it is possible that a strong ethnic identity mediates the potential effects of felt pressure on Latino youth. Thus, there is a demonstrated need to explore the relationship between gender identity, ethnic identity, and selfesteem in Latino male youth (Mora, 2012).

\section{Problem Statement}

Research has demonstrated a significant positive relationship between having a strong ethnic identity and high self-esteem (Umaña-Taylor, 2004), but there is limited research on how this relationship interacts with gender identity in Latino male youth (Mora, 2012). Understanding what facets of identity have a positive effect on self-esteem in this population is of particular importance because research shows that Latino male youth are at-risk for negative health outcomes (Corona, et al., 2009), including low self-esteem (Twenge \& Crocker, 2000). Selfesteem, one of the most widely used measurements of psychological adjustment in gender identity research (Whitley, 1983), is an evidenced protector from mental distress in children and adolescents (Hosogi, Okada, Fujii, Noguchi, \& Watanabe, 2012). Therefore, it is of clinical and empirical importance to investigate the relationship between gender identity, ethnic identity, and 
self-esteem in this understudied and at-risk population. This study is an investigation of these relationships. Specifically, this study aims to explore how gender typicality and gender contentedness are related to Latino boys' self-esteem, and how ethnic identity mediates the relationship between felt pressure and self-esteem.

\section{Hypotheses}

1. There will be a significant positive correlation between gender typicality and selfesteem.

2. There will be a significant positive correlation between gender contentedness and self-esteem.

3. There will be a significant positive correlation between ethnic identity and selfesteem.

4. Ethnic identity will significantly mediate the relationship between felt pressure and self-esteem in a positive direction (see Figure 1).

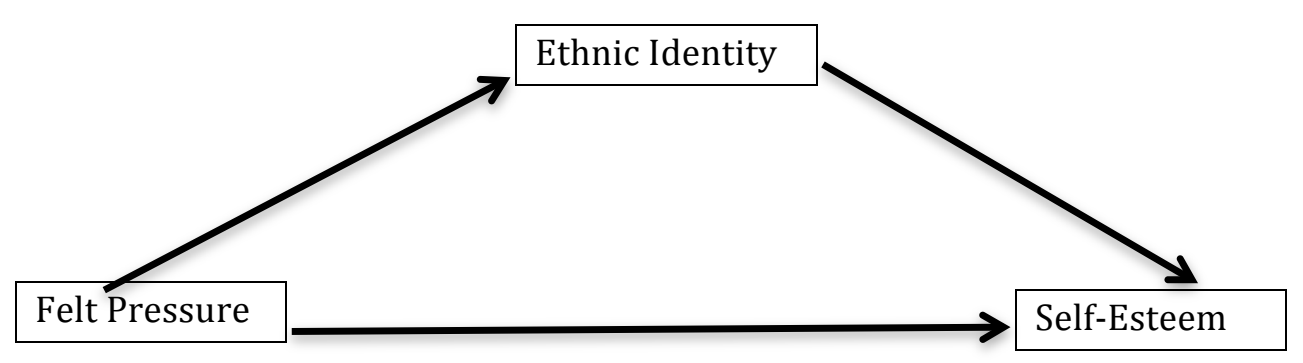

Figure 1. Diagram shows flow of mediation model for hypotheses 4. 


\section{CHAPTER 3}

\section{METHODS}

\section{Participants}

The study's all-male participants were members of Youth in Action (YIA), a yearlong, school-based intervention program for boys identified as at-risk for gang association and/or membership (participants had one YIA class before the assessment period began). YIA serves elementary, middle school and high school students who reside on the Central Coast of California. Youth are referred to the program through a collaboration between school officials, community based organizations, and the County's Probation Department.

The sample consisted of 55 boys $(n=55)$ who were ages 10 to 14 , with an average age of $12.42(\mathrm{SD}=.99)$. Of the 55 boys, $43(78.2 \%)$ self-identified as Hispanic, Latino, or Mexican American; 2 (3.6\%) self-identified as White, Caucasian, or European American; 9 (16.4\%) selfidentified as having parents from two different ethnic groups; and $1(1.8 \%)$ self-identified as other. For more descriptive details on the participants, please refer to Table 1. 
Table 1

Summary of descriptive statistics for all-male participants.

$N=55$.

\begin{tabular}{|c|c|c|}
\hline & Frequency & Percent \\
\hline \multicolumn{3}{|l|}{ AGE } \\
\hline 10 & 2 & 3.6 \\
\hline 11 & 10 & 18.2 \\
\hline 12 & 10 & 18.2 \\
\hline 13 & 29 & 52.7 \\
\hline 14 & 4 & 7.3 \\
\hline \multicolumn{3}{|l|}{ GRADE } \\
\hline 5th & 3 & 5.5 \\
\hline 6th & 13 & 23.6 \\
\hline 7 th & 14 & 25.5 \\
\hline 8th & 25 & 45.5 \\
\hline \multicolumn{3}{|l|}{ SCHOOL } \\
\hline Elementary School & 4 & 7.3 \\
\hline Middle School & 51 & 92.7 \\
\hline \multicolumn{3}{|l|}{ COUNTY } \\
\hline North County & 31 & 56.4 \\
\hline South County & 24 & 43.6 \\
\hline \multicolumn{3}{|l|}{ FATHER ETHNIC IDENTITY } \\
\hline Black or African American & 0 & 0 \\
\hline $\begin{array}{l}\text { Hispanic, Latino, Mexican } \\
\text { American }\end{array}$ & 46 & 88.5 \\
\hline $\begin{array}{l}\text { White, Caucasian, European } \\
\text { American }\end{array}$ & 4 & 7.7 \\
\hline $\begin{array}{l}\text { Mixed; parents from two } \\
\text { different ethnic groups }\end{array}$ & 2 & 3.8 \\
\hline \multicolumn{3}{|l|}{ MOTHER ETHNIC IDENTITY } \\
\hline Black or African American & 2 & 3.8 \\
\hline $\begin{array}{l}\text { Hispanic, Latino, Mexican } \\
\text { American }\end{array}$ & 44 & 83 \\
\hline $\begin{array}{l}\text { White, Caucasian, European } \\
\text { American }\end{array}$ & 5 & 9.4 \\
\hline $\begin{array}{l}\text { Mixed; parents from two } \\
\text { different ethnic groups }\end{array}$ & 2 & 3.8 \\
\hline
\end{tabular}


Instruments

Gender identity was measured using the Gender Typicality, Felt Pressure and Gender Contentedness scales developed by Egan and Perry (2001). Carver et al. (2003) said their multidimensional analysis study "strengthens the construct and discriminant validity of the gender identity constructs and scales" (p.105) by measuring the relationship between psychosocial adjustment and gender identity in different ways. Though this may lend validation to the multidimensional model, more cross-cultural validation research will be needed in the future to ensure the gender identity scales are measuring culturally appropriate constructs.

The 5-item Gender Typicality scale, which measures one's perceived similarity to samesex individuals, has a reported Cronbach alpha coefficient of .78 (Egan \& Perry, 2001). In this study, the scale had a Cronbach alpha coefficient of .78. Subjects read the two coinciding sentences, select which sentence best describes them, and then circle whether the sentence is "Very True" or "Sort of True" for them.

A sample question is:

Some boys feel they are

BUT Other boys feel they are

different from other boys similar to other boys.

$\begin{array}{llll}\text { Very true } & \text { Sort of } & \text { Very true } & \text { Sort of } \\ \text { for me } & \text { true for me } & \text { for me } & \text { true for me }\end{array}$

The 6-item Gender Contentedness scale, which measures satisfaction with one's sex assignment, has a reported Cronbach alpha coefficient of .79 (Egan \& Perry, 2001). In this study, the scale had a Cronbach alpha coefficient of .74. The scale was presented to the participants in the same format as the Gender Typicality scale. A sample question is: "Some boys like being a boy BUT Other boys don't like being a boy. 
The 7-item Felt Pressure scale, which measures how much pressure a child is experiencing from parents, peers and the self to conform to gender stereotypes, has a Cronbach alpha coefficient of .92 (Egan \& Perry, 2001). In this study, the scale had a Cronbach alpha coefficient of .80. Subjects circle one of four responses to a statement, including Not at all true for me, A little true for me, Pretty true for me, or Very true for me. A sample statement is:

\begin{tabular}{|c|c|c|c|}
\hline $\begin{array}{l}\text { The boys I know would be } \\
\text { upset if I wanted to play }\end{array}$ & $\begin{array}{l}\text { Not at all } \\
\text { true for me }\end{array}$ & $\begin{array}{l}\text { A little true } \\
\text { for me }\end{array}$ & $\begin{array}{l}\text { Pretty true } \\
\text { for me }\end{array}$ \\
\hline
\end{tabular}
with girls' toys.

The Rosenberg Self-Esteem Scale (RSES; Rosenberg, 1989) was used to measure participants' global self-esteem. This 10-item Likert scale asks subjects to Strongly Agree (SA), Agree (A), Disagree (D), or Strongly Disagree (SD) with a statement regarding global attitudes of their self. This is one of the most popular self-esteem scales used in research and has a reported Cronbach Alpha coefficient of .88 (Greenberg, Chen, Dmitrieva \& Farruggia, 2003) and has demonstrated cross-cultural validation with Latino adolescents (Supple \& Plunkett, 2011). However, it's important to note that, "there is no simple method that allows researchers to confidently establish whether...global self-esteem have structural equivalence across cultures" (Schmitt \& Allik, 2005, p. 624). Despite this concern, Schmitt and Allik (2005) concluded that the factor structure across their sample of 53 countries was largely invariant, supporting the scale's structural equivalence.

In this present study, the RSES had a Cronbach alpha coefficient of .67. A sample RSES question is:

On a whole, I am satisfied with my self. $S A \quad A \quad D \quad S D$

The Ethnic Identity Teen Conflict Survey (EITCS; Bosworth \& Espelage, 1995) measures ethnic pride and respect for differences among middle school students in the sixth through eighth grades, and has a reported Cronbach alpha coefficient of .73 (Bosworth \& Espelage, 1995). While the scale has demonstrated internal reliability and consistency, there seems to be a lack of literature concerning its validation. For instance, in a compendium of scales that measure 
constructs related to youth, the EITCS is included in the list of scales that measure ethnic identity. However, only the scale's internal consistency of .73 is listed under the reliability/validity column, suggesting that more studies are needed to determine the construct validity of this scale (Dahlberg, L.L, Toal, S.B., Swahn, M., \& Behrens, C.B., 2005).

In this study, the EITCS had a Cronbach alpha coefficient of .82. The 6-item scale asks participants to select one of five responses to a statement, including Never, Not often, Sometimes, A lot, or Always. A sample statement is:

I enjoy learning about my own ethnic group, such as its history, traditions, and customs.

\section{Procedure}

Administration

All measures were administered at each one of the six schools during a Youth in Action class period. The principal investigator administered assessments with assistance from YIA staff. All data was collected immediately after the questionnaires were completed.

\section{Precautions taken}

Informed consent was obtained from the participating youth's parent/guardian and consent forms were provided in Spanish and English. An informed consent form was also provided for the youth participants and was explained to them in oral and written form. Youth participants were informed that they could refuse to answer any or all of the questions in the assessments without penalty. A Youth in Action staff member and the principal investigator were present during the administration of the questionnaires in order to answer participants' questions or concerns. If a participant became distressed before, during or after completing the questionnaires, he was referred to an appropriate Youth in Action staff member and/or school counselor. However, there was no indicated distress during the assessment period. 
Confidentiality

After having described informed consent to the youth through written and oral explanations, and after having obtained consent from the youth's parent/guardian, youth who chose to participate in this study were given an identification number. This number protected the youth's identity, so names were not required to complete the questionnaires. The number roster was only accessible to the principal investigator and to the thesis advisor.

Participant confidentiality was to be broken only if it the minor was in danger of being abused or neglected, or if the participant was in danger of hurting oneself or another individual. If any of these limits to confidentiality were met, the appropriate authorities were to be notified immediately for the participant's safety and protection. The principal investigator and Thesis Advisor were responsible for determining whether or not a child abuse/neglect report was necessary. No such incidents occurred during this study.

Incentives

No incentives for participants were used in this research project.

\section{Statistical Analyses}

To examine the relationship between gender identity, ethnic identity, and self-esteem, Pearson correlations coefficients were conducted using Gender Typicality, Felt Pressure, and Gender Contentedness scales (Egan and Perry, 2001), the Ethnic Identity Teen Conflict Survey (Bosworth \& Espelage, 1995), and the Rosenberg Self-Esteem Scale (Rosenberg, 1989) to asses for correlations between gender typicality and self-esteem, gender contentedness and selfesteem, and ethnic identity and self-esteem. Three regression equations were conducted to determine if ethnic identity mediated the relationship between felt pressure (the independent variable) and self-esteem (the dependent variable) (Baron \& Kenny, 1986). 


\section{CHAPTER 4}

\section{RESULTS}

The results of 55 respondents were analyzed in this study. A minimum reasonable power for this sample size is .80 , and the calculated power under these conditions was .99 with alpha $\leq$ .05 (Cohen, 1988). Analyses were run to examine any outliers. Two outliers were found to be farther than 1.5 interquartile ranges for the self-esteem variable. After re-examining the raw data, it was found that one of the outliers had only filled out 2 of the 10 self-esteem questions, so his self-esteem answers were discarded. The second outlier had such a low self-esteem score compared to other participants that it was decided to keep only the self-esteem scores that totaled more than 10 out of 30 . This discarded the second outlier's self-esteem answers. Therefore, $n$ was reduced from 57 to 55 .

After conducting the Pearson correlations coefficients and the regression analyses to test the mediation model with alpha set at .05, two of the four hypotheses were supported. Exploratory analyses highlighted several significant correlations and one marginally significant mediation model that were not originally hypothesized, but are of clinical and empirical importance. See Table 2 for listwise descriptive statistics of the variables.

Table 2

Listwise descriptive analysis of measures

\begin{tabular}{lccccc}
\hline Measures & $\mathrm{N}$ & Mean & Std. Deviation & Minimum & Maximum \\
\hline Felt Pressure & 54 & 3.22 & 0.75 & 1.43 & 4 \\
Gender & 52 & 3.72 & 0.44 & 2.5 & 4 \\
Contentedness & 52 & 2.96 & 0.81 & 1.4 & 4 \\
Gender Typicality & 55 & 20.85 & 4.03 & 11 & 30 \\
Self Esteem & 55 & 4.17 & 0.74 & 1 & 5 \\
Ethnic Identity & & & & & \\
\hline
\end{tabular}


$H_{1}$ : There will be a significant positive correlation between gender typicality and selfesteem (see Table 3 for Pearson correlation coefficients).

The correlation between gender typicality and self-esteem was not found to be statistically significant, $r(52)=.20, p=.16$. These results indicate that the boys' levels of selfesteem were not related to how typical they felt of other boys.

$\mathrm{H}_{2}$ : There will be a significant positive correlation between gender contentedness and selfesteem.

The correlation between gender contentedness and self-esteem was found to be statistically significant, $r(52)=.31, p=.03$. These results indicate that the boys who reported being satisfied with their gender assignment also reported having higher self-esteem.

$\mathrm{H}_{3}$ : There will be a significant positive correlation between ethnic identity and self-esteem.

The correlation between ethnic identity and self-esteem was found to be statistically significant, $r(55)=.45, p<.01$. These results indicate that the boys who reported having a strong ethnic identity also had higher self-esteem.

Table 3

Correlation Coefficient Matrix for Variables

\begin{tabular}{lccccc}
\hline & FP & GC & GT & SE & El \\
\hline FP & 1 & & & & \\
GC & $.28^{*}$ & 1 & & & \\
GT & 0.2 & $.36^{* *}$ & 1 & & \\
SE & 0.05 & $0.31^{*}$ & 0.2 & 1 & \\
El & 0.02 & $0.33^{*}$ & 0.12 & $.45^{* *}$ & 1 \\
\hline
\end{tabular}

Note: Two-tailed. ${ }^{\star} p<.05 .{ }^{* *} p<.01$. FP $=$ Felt Pressure, GC $=$ Gender Contentedness, $G T=$ Gender Typicality, SE = Self-Esteem, and EI = Ethnic Identity.

\section{$\mathrm{H}_{4}$ : Ethnic identity will significantly mediate the relationship between felt pressure and self-esteem in a positive direction.}

The hypothesized mediation model was analyzed by conducting a series of regressions as recommended by Baron and Kenny (1986). According to Baron and Kenny (1986), four 
conditions must be met for a variable to be considered a mediator. One, the predictor (felt pressure) must be significantly associated with the hypothesized mediator (ethnic identity). Two, the predictor (felt pressure) must be significantly associated with the dependent measure (selfesteem). Three, the mediator (ethnic identity) must be significantly associated with the dependent variable (self-esteem). Fourth, the impact of the predictor (felt pressure) on the dependent measure (self-esteem) must be less after controlling for the mediator (ethnic identity). Since it would be unusual in psychology for this effect to be reduced from significance to zero, the degree to which the effect is reduced (e.g., the change in regression coefficients) is an indicator of the potency of the mediator (Baron \& Kenny, 1986).

The four conditions above were tested with three multiple regression analyses for the dependent variable, self-esteem (see Table 4). Regression analysis revealed a non-significant relationship between felt pressure and ethnic identity $(r=.02, b=.02, p=.87)$; a non-significant relationship between felt pressure and self-esteem $(r=.05, b=.28, p=.71)$; and a nonsignificant mediator of ethnic identity $(r=.45, b=.23, p=.74)$. Results demonstrate that the hypotheses of ethnic identity mediating the relationship between felt pressure and self-esteem was not supported. 
Table 4

Summary of Regression Analysis for Variables Predicting Self-Esteem within a Mediator Model (Hypotheses 4)

Stage 1

\begin{tabular}{|c|c|c|c|c|}
\hline \multirow[b]{2}{*}{ Predictor (IV) } & \multicolumn{3}{|c|}{$\frac{\text { Ethnic Identity }}{\text { (DV) }}$} & \multirow[b]{2}{*}{ Sig. } \\
\hline & $\underline{B}$ & $\underline{S E} \underline{B}$ & $\underline{B}$ & \\
\hline Felt Pressure & 0.02 & 0.14 & 0.02 & 0.87 \\
\hline
\end{tabular}

Stage 2

\section{Self-Esteem}

(DV)

\begin{tabular}{lcccc} 
Predictor (IV) & $\underline{B}$ & $\underline{\underline{S E}} \underline{B}$ & $\underline{B}$ & Sig. \\
\hline Felt Pressure & 0.28 & 0.75 & 0.05 & 0.71 \\
\hline
\end{tabular}

Note: $R=.05{ }^{*} p<.05,{ }^{* *} p<.01$.

Stage 3

\section{Self-Esteem}

(DV)

\begin{tabular}{lcccl} 
Predictors (IV) & $\underline{B}$ & $\underline{S E} \underline{B}$ & $\underline{B}$ & Sig. \\
\hline Felt Pressure & 0.23 & 0.68 & 0.04 & 0.74 \\
Ethnic Identity & 2.46 & 0.69 & 0.45 & $0.001^{\text {** }}$ \\
\hline
\end{tabular}

Note: $\mathrm{R}=.45 .{ }^{*} \mathrm{p}<.05,{ }^{* *} \mathrm{p}<.01$. 


\section{Exploratory Analyses}

Several other significant relationships were determined in the analyses that were not originally hypothesized, including three statistically significant correlations and one marginally significant mediation model.

The correlation between gender contentedness and felt pressure was found to be statistically significant, $r(51)=.28, p=.04$. These results demonstrate a significant relationship between boys who feel pressure to conform to male stereotypes and being satisfied with one's gender assignment.

The correlation between gender contentedness and gender typicality was found to be statistically significant, $r(52)=.36, p=.01$. These results indicate that a relationship exists between boys who feel typical of other boys and being satisfied with one's gender assignment.

The correlation between gender contentedness and ethnic identity was found to be statistically significant, $r(52)=.33, p=.02$. These results show a significant relationship between boys who are satisfied with their gender assignment and having a strong ethnic identity.

Given the statistically significant relationship found between gender contentedness and self-esteem $(p<.05)$, gender contentedness and ethnic identity $(p<.05)$, and ethnic identity and self-esteem $(p<.01)$, three multiple regression analyses were conducted to determine if ethnic identity mediated the relationship between gender contentedness and self-esteem (see Figure 2). Results showed that all four conditions were met for a variable to be considered a mediator (Baron \& Kenny, 1986), and that results were marginally significant (see Table 5).

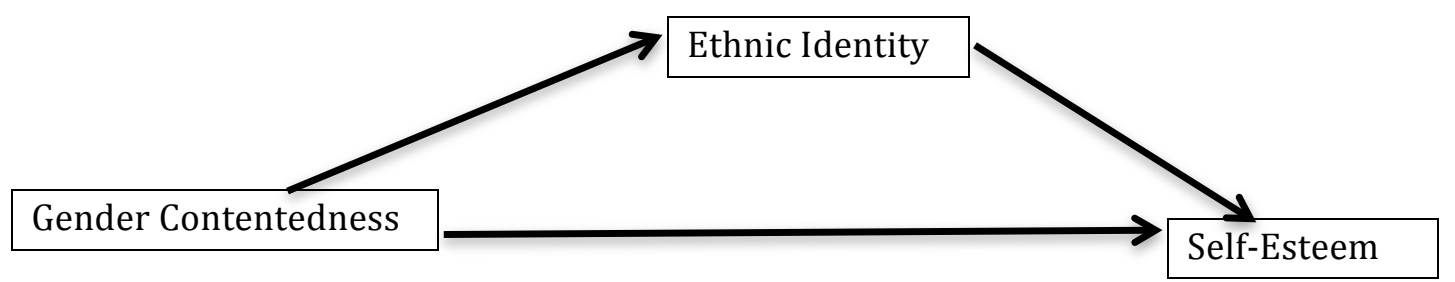

Figure 2. Diagram shows flow of mediation model for exploratory analyses. 
Regression analyses revealed a significant positive relationship between gender contentedness and ethnic identity $(r=.33, B=.48, p=.02)$. It also revealed a significant positive relationship between gender contentedness and self-esteem $(r=.31, B=2.56, p=.03)$. When ethnic identity is controlled for, the relationship between gender contentedness and self-esteem is reduced to a non-significant level $(r=.40, B=1.82, \quad p=.12)$. While the mediating conditions have been satisfied, the significance level of ethnic identity as the mediating variable, $(r=.45, B=$ $1.56, p=.056)$, indicates that this mediation model is marginally significant. These results demonstrate that having a strong ethnic identity marginally mediates the relationship between feeling satisfied with one's gender assignment and having high self-esteem. 
Table 5

Summary of Regression Analysis for Variables Predicting Self-Esteem within a Mediator Model (Exploratory Analysis)

Stage 1

\begin{tabular}{lcccc}
\hline \multicolumn{5}{c}{ Ethnic Identity } \\
Predictor (IV) & $\underline{B}$ & $\underline{\text { SE B }}$ & $\underline{B}$ & Sig. \\
\hline Gender Contentedness & 0.48 & 0.19 & 0.33 & $0.02^{*}$ \\
\hline
\end{tabular}

Note: $\mathrm{R}=.33 .{ }^{*} \mathrm{p}<.05,{ }^{* *} \mathrm{p}<.01$.

Stage 2

\begin{tabular}{|c|c|c|c|c|}
\hline \multirow[b]{2}{*}{ Predictor (IV) } & \multicolumn{3}{|c|}{$\frac{\text { Self-Esteem }}{(\mathrm{DV})}$} & \multirow[b]{2}{*}{ Sig. } \\
\hline & B & SE B & $B$ & \\
\hline Gender Contentedness & 2.56 & 1.13 & 0.31 & $0.03^{*}$ \\
\hline
\end{tabular}

Note: $\mathrm{R}=.31 .{ }^{*} \mathrm{p}<.05,{ }^{* *} \mathrm{p}<.01$.

Stage 3

\begin{tabular}{lcccc}
\hline & \multicolumn{2}{c}{ Self-Esteem } \\
Predictors (IV) & $\underline{B}$ & $\underline{\text { SE B }}$ & $\underline{B}$ & Sig. \\
\hline Gender Contentedness & 1.82 & 1.16 & 0.22 & 0.12 \\
Ethnic Identity & 1.56 & 0.8 & 0.27 & $0.056^{*}$ \\
\hline
\end{tabular}

Note: $\mathrm{R}=.45 .{ }^{*} \mathrm{p}<.1{ }^{* *} \mathrm{p}<.05,{ }^{* * *} \mathrm{p}<.01$. 


\section{CHAPTER FIVE}

\section{DISCUSSION}

It is only in the $21^{\text {st }}$ century that gender identity and its relationship to adjustment, particularly self-esteem, has been empirically examined within a multidimensional framework (Egan \& Perry, 2001). Specifically, gender typicality, gender contentedness, and felt pressure have been used to capture facets of gender identity in pre-adolescent and adolescent youth. Cultural factors that could potentially affect such a relationship, such as having a strong ethnic identity, have not been closely investigated in past studies using this multidimensional framework. This study sheds new light on the relationship between gender identity, ethnic identity, and selfesteem in Latino at-risk youth, an understudied population in gender identity literature (Mora, 2012). The results of this study demonstrate support for two of the four hypotheses, as well as several significant relationships not originally hypothesized but of which are clinically and empirically meaningful.

It was hypothesized that gender typicality would be correlated to self-esteem, but this relationship was not supported. This was surprising, given that the relationship was found to be significant in prior studies using the multidimensional analysis (Carver et al., 2003; Egan \& Perry, 2001; Yunger et al., 2004) and among Hispanic youth (Corby et al., 2007). It was also hypothesized that the relationship between felt pressure and self-esteem would be mediated by ethnic identity. Results did not support this relationship, as there was no significant correlation between felt pressure and self-esteem or felt pressure and ethnic identity.

A possible explanation for these results rests in the idea that ethnic identity may at times play a more influential role than gender identity in minorities. Corby et al. (2007), when discussing the lack of significant correlations between gender identity and adjustment among Black youth in their study, state that Black preadolescents are facing a racial minority identity and this may be causing other parts of their identity to be less pertinent at that age. Zinn (1980) suggests that gender identity in Latinos "is important for those who do not have access to other sources of 
social identity" (p.23) and that "to be hombre [man] may be a reflection of both ethnic and gender components and take on greater significance when other sources of social identity are structurally blocked" (p.23).

A study examining racial ethnic identity over time in native Canadian children, who are a collectivist culture like Latino culture, found that being an Aboriginal was considered more important to the children than their own gender identity (Corenblum \& Armstrong, 2012). The authors add that it seems that children begin thinking about their personal and collective identities when they are relatively young. It is possible that feeling typical or atypical of one's ethnic group, and feeling more pressure to conform to one's ethnic groups' norms, is emphasized more than one's gender identity in Latino youth. It seems that more research is needed on ethnic and gender identity during the Latinos' pre-adolescent and adolescent developmental period to clarify the level of importance of each identity dimension.

It is also important to take note of the specific population used in this study. All of the boys in this study have been identified as being at-risk for gang association and therefore eligible to be a part of Youth In Action, a school-based intervention program. According to Hill, Howell, Hawkins, and Battin-Pearson (1999), research shows that there are family risk factors (e.g. high family conflict, low family bonding), school risk factors (e.g. academic failure), and peer risk factors (e.g. being with peers who engage in risky behavior) that separate gang members from non-gang members. The boys in this study have a mix of these risk factors, as YIA bases their member selection on evidence of past conduct behavior, poor school performance and school disciplinary action, and family associations/memberships with gangs. It is possible that the participants are coping with whether they feel typical or atypical of peers and family members who are in a gang, and also coping with pressure to conform to the gang lifestyle. The YIA boys are facing the challenge of identifying with a gang or not, and this could very well be a source of more conflict than concern about how typical they are in their "maleness" or male pressure to conform to male stereotypes. 
Though gender typicality and felt pressure were not strongly associated with self-esteem, the hypothesis that having a strong ethnic identity would be correlated with self-esteem was supported. These results are consistent with previous findings (Brittian, Umaña-Taylor \& Derlan, 2012; Umaña-Taylor, 2004) and demonstrate the importance of a developed ethnic identity on youths' levels of adjustment. Feeling part of the social community is an enormous component of racial-ethnic identity (Corenblum \& Armstrong, 2012) and the fact that ethnic identity and selfesteem are related coincides well with the Latino collectivist culture and how the self is viewed as an extension of the family and community (Piña-Watson et al., 2013).

A strong ethnic identity may have particular salience to this study's population. The YIA participants are at-risk of joining a gang, and gangs tend to be ethnically homogenous. Adolescents may join gains to explore their own ethnic identity, and some Mexican American gangs employ their ethnic identity to garner strength (Knight, Losoya, Cho, Chassin, Cota-Robles \& Williams, 2012; Vigil, 1988, 2003). A strong ethnic identity needs to be harnessed in a way that invites positive community interaction and promotes a well-adjusted self-concept, rather than youth finding ethnic solidarity through gang affiliation or membership.

Lastly, it was hypothesized that gender contentedness and self-esteem would be positively correlated, and this relationship was found to be statistically significant. These results are consistent with previous research, where Carver et al. (2003) found that gender contentedness significantly predicted self-esteem. The authors add, "The feeling of being at home or not at home in one's body is almost certain to affect satisfaction with the self' (p.99). Research shows that dissatisfaction with one's gender assignment, to the point where one may qualify for Gender Identity Disorder, has been linked with many issues, including peer relationship problems and depression (Ceglie, 2000), both of which can effect a person's level of self-esteem (Gorrese, 2013; Orth \& Robins, 2013). Being happy with one's gender suggests that the person is happy with a part of their identity, potentially contributing to a person having positive feelings towards themselves. 


\section{Exploratory Analyses}

It was proposed that gender contentedness would only be related to self-esteem. After conducting the Pearson correlation coefficients, it was found that gender contentedness was also significantly positively related to gender typicality, felt pressure, and ethnic identity. The first relationship, gender contentedness and gender typicality, suggests that those who feel happy with their assigned gender also feel typical of same sex peers. While this relationship was not hypothesized, it is not surprising since being unhappy with one's gender and feeling atypical of one's gender are required to meet the criteria for Gender Identity Disorder (American Psychiatric Association, DSM-IV, 2000), implying that there is a strong relationship between these two constructs on a person's psychological adjustment.

The second relationship, gender contentedness and felt pressure, suggests that those who have high satisfaction with their gender are also experiencing high felt pressure to conform to gender stereotypes. Egan and Perry's (2001) Felt Pressure scale was designed to measure how much pressure children feel from parents, peers, and the self to participate in gendercongruent conduct. It is possible that one of the pressures a child experiences regarding gender stereotypes is to actually like his or her own gender assignment. Gagne and Tewksbury (1998) say that there is an "ideological presumption that gender will correlate with the sex assigned at birth. Individuals who seek to challenge this binary system of gender... are likely to be stigmatized, ostracized, and labeled mentally ill" (p. 81). It may be that not liking one's own sex is challenging this binary system of gender, particularly in the Latino culture where the man historically has a more dominating role. It could be disconcerting for a boy to not want to be associated with the "strong" gender, as not wanting to be associated with strength may go against the very underpinnings of being male. Uncovering how much pressure one feels to actually like one's gender assignment, and not just to act in a gender-congruent manner, is an important construct to explore in gender identity research.

The third relationship, gender contentedness and ethnic identity, indicates that those who are happy with their gender also have a strong ethnic identity. Given the significant positive 
relationship between gender contentedness and ethnic identity, ethnic identity and self-esteem, and gender contentedness and self-esteem, an exploratory analysis was conducted to see if ethnic identity mediated the relationship between gender contentedness and self-esteem. Results were marginally significant $(p=.056)$. This study's participants were all male and males tend to have the more dominating role in the Latino culture (Herrera, Owns, \& Mallinckrodt, 2013). Perhaps the Latino boys who feel strongly connected to their ethnic identity have internalized this power differentiation and therefore feel content with being the more dominant gender in their culture. It is clear that more research is needed on the relationship dynamics between ethnic identity and gender identity, and how these dynamics interact with self-esteem.

\section{Limitations}

There are several limitations to this study that are worth noting. First, the sample is comprised of a small, all-male population who are at-risk of gang membership and/or affiliation. That indicates limited generalizability and little variability. Second, there may have been increased social desirability in answering the assessment questions, as the boys self-reported their feelings about a highly charged topic while in a classroom with other boys. For instance, several boys wondered why anyone would feel sorry they are boys after answering Gender Contentedness scale questions. One boy even asked the principal investigator if the questions were meant to find out if he was gay. Furthermore, some participants expressed Latino pride by thumping their chest and saying "Mexican" after the assessments were completed. While these are simply assessment observations, the verbal reactions produced by written questions raises the idea of conducting more qualitative research on these provocative issues.

Third, while the majority of the sample was of Latino heritage, Latino subcultures (e.g. Mexican, Puerto Rican, etc.) were not distinguished so there could still be differences in variable relationships among these distinct cultural groups. Lastly, the questionnaires were only provided in English. While all children spoke English, some came from homes where Spanish was the first language, and a few participants had trouble understanding the wording of the questionnaires. For example, several students needed clarification on what "spare time" meant on Item 2 of the 
"What I am Like Part II" questionnaire (Gender Typicality scale, Egan \& Perry, 2001) and what the definition for "ethnicity" was on the "My Ethnic Identity" questionnaire (Ethnic Identity Teen Conflict Survey, Bosworth \& Eseplage, 1995).

Some students also had difficulty understanding the word "inclined" on Item 3 of the Rosenberg Self-Esteem Scale (Rosenberg, 1989). The RSES has demonstrated good internal validity and reliability in the past with a Cronbach alpha coefficient of .88 (Greenberg, et al., 2003). However, in this study the RSES had a Cronbach alpha coefficient of .67, showing less internal reliability and consistency. While the RSES's cross-cultural validity and dimensionality has been evidenced with Latino adolescents (Supple \& Plunkett, 2011), Schmitt and Allik (2005) found that Item 8 on the RSES scale, "I wish I could have more respect for myself," had both positive and negative factor loadings among different countries, including Mexico. The authors state that, "These findings indicate that Item 8 of the RSES contains a degree of ambiguity that may cause it to be easily misinterpreted in some cultures" (p. 627). Incidentally, some of the participants in this sample had difficulty comprehending Item 8 as well. It is possible that some students did not ask for help in understanding certain questions on the scale and it is also possible that the self-esteem construct may manifest itself differently in Latino at-risk youth than in other cultural groups. For instance, since Latinos are a collectivist culture, which emphasizes interdependent relationships (Vandello \& Cohen, 1999), it may be that examining self-worth through a more community-oriented framework is perhaps more pertinent to this sample's population.

Implications of Study and Future Directions

The findings of this study, as well as the sample used in this study, have clinical and research implications. Regarding clinical importance, it is clear that having healthy self-esteem is related to one's psychological adjustment. For instance, self-esteem was higher in resilient adolescents than in vulnerable adolescents (Dumont \& Provost, 1998), and research shows that self-esteem is associated with good social and health behaviors while poor self-esteem can lead to internalizing (e.g. suicide) and externalizing (e.g. substance use) problems (Mann, Hosman, \& 
Schaalma, 2004). Therefore, factors promoting self-esteem will help with enhancing healthy psychological adjustment.

This study also reinforces the importance of identity work with preadolescent and adolescent clients. As identity development piques during adolescence (Erikson, 1950), it is imperative to consider youths' understanding of their own identity and how it relates to their feelings of self-worth. As research has shown, gender identity—specifically gender contentedness in this study_and ethnic identity are significantly related to self-esteem. It seems to be especially crucial to acknowledge the clear connection between ethnic identity and selfesteem. If a treatment program's goals are to promote self-esteem in Latinos, it is important to consider the strength of the client's connection to his own ethnic identity and to explore his connection with his ethnic community. While a causal relationship between the two constructs cannot be determined by this study, it seems that clinicians need to pay attention to developing a strong ethnic identity if the clinical goal is to improve Latino's self-esteem. Thinking about how these facets are interconnected, and what being a Latino means as a male and as an ethnic minority, warrants future clinical considerations.

Regarding empirical importance, this study sheds light on what factors are related to Latino boys' self-esteem during a critical developmental period in their identity. With so many identity frameworks emerging during adolescence-gender, ethnicity, and in this particular case, gang identification-it is important to research which identities may be more prominent than others at a given time, thus understanding which ones will have the most influential impact on adjustment. Additionally, many studies have focused on investigating the negative outcomes on Latino mental and behavioral health; understanding what contributes to positive outcomes is of equal importance (Piña-Watson, et al., 2013). More research needs to also be conducted on multicultural populations using the multidimensional analyses (Corby et al., 2007), particularly longitudinal studies where one can assess the impact of gender identity and ethnic identity over the adolescent developmental period. 
An especially important future direction for gender identity, ethnic identity, and selfesteem research is developing scales that demonstrate strong construct validity across cultures. Due to the exploratory nature of this present study, one cannot determine the validity of these specific measures used with the Latino, male, at-risk youth population. This makes it harder to draw upon clinical inferences. Can these gender identity, ethnic identity, and self-esteem scales be used with Latino at-risk males in clinical settings? Do these scales measure the same constructs across cultures? Are these constructs even relevant to different cultures? It is important to investigate how the constructs of gender identity, ethnic identity, and self-esteem are both similar and different across cultural contexts in order to develop measures that capture their specific meanings. The applicability of these measures in clinical settings with Latino, male, atrisk youth can then be determined and utilized in culturally appropriate treatment plans. 


\section{References}

Alpert-Gillis, L.J. \& Connell, J.P. (1989). Gender and sex-role influences on children's self-esteem. Journal of Personality, 57(1), 97-114.

American Psychiatric Association. (2000). Diagnostic and statistical manual of mental disorders (4th ed., text rev.). Washington, DC: Author.

Antill, J.K. \& Cunningham, J.D. (1979). Self-esteem as a function of masculinity in both sexes. Journal of Consulting and Clinical Psychology, 47(4), 783-785.

Arciniega, G.M., Anderson, T.C., Tovar-Blank, Z.G., \& Tracey, Terence J.G. (2008). Toward a fuller conception of machismo: Development of a traditional machismo and caballerismo scale. Journal of Counseling Psychology, 55(1), 19-33.

Auster, C.J. \& Ohm, S. C. (2000). Masculinity and femininity in contemporary American society: A reevaluation using the Bem Sex-Role Inventory. Sex Roles, 43(7/8). 499-528.

Bailey, .C., Hendrick, C., \& Hendrick, S.S. (1987). Relation of sex and gender role to love, sexual attitudes, and self-esteem. Sex Roles, 16(11/12), 637-648.

Baron, R.M. \& Kenny, D. A. (1986). The moderator-mediator variable distinction in social psychological research: conceptual, strategic, and statistical considerations. Journal of Personality and Social Psychology, 51(6), 1173-1182.

Beere, C. A. (1990). Sex and gender issues: A handbook of tests and measures. Westport, CT: Greenwood Press.

Bem, S. (1974). The measurement of psychological androgyny. Journal of Counseling and Clinical Psychology, 42(2), 155-162.

Bem, S.L. (1977). On the utility of alternative procedures for assessing psychological androgyny. Journal of Consulting and Clinical Psychology, 45, 196-205. 
Bem, S. (1981). Gender schema theory: A cognitive account of sex-typing.

Psychological Review, 88(4), 354-364.

Block, J. (1973). Conceptions of sex role: Some cross-cultural and longitudinal perspectives. American Psychologist, 28, 512-526.

Boldizar, J.P. (1991). Assessing and sex typing and androgyny in children: The children's sex role inventory. Developmental Psychology, 27(3), 505-515.

Bosworth, K. \& Espelage, D. (1995). Teen Conflict Survey, Center for Adolescent Studies, Indiana University. Bloomington, IN: unpublished manuscript.

Bracey, J.R., Bamaca, M.., \& Umaña-Taylor, A.J. (2004). Examining ethnic identity and self-esteem among biracial and monoracial adolescents. Journal of Youth and Adolescence, 33(2), 123-132.

Brindis, C., Wolfe, A.L., McCarter, V., Ball, S., \& Starbuck-Morales, S. (1995). The associations between immigrant status and risk-behavior patterns in Latino adolescents. Journal of Adolescent Health, 17(2), 99-105.

Brittian, A.S., Umana-Taylor, A.J., \& Derlan, C.L. (2013). An examination of biracial college youths' family ethnic socialization, ethnic identity, and adjustment: Do self-identification labels and university context matter? Cultural Diversity and Ethnic Minority Psychology, 19(2), 177-189.

Broverman, I.K., Broverman, D.M., Clarkson, F. E., Rosenkrantz, P.S, \& Vogel, S.R. (1970). Sex role stereotypes and clinical judgments of mental health. Journal of Consulting and Clinical Psychology, 34, 1-7.

Burnett, J., Anderson, .P., \& Heppner, P.P. (1995). Gender roles and self-esteem: A consideration of environmental factors. Journal of Counseling \& Development, 73, 323-326. 
Bussey, K. \& Bandura, A. (1999). Social cognitive theory of gender development and differentiation. Psychological Review, 106, 676-713.

Carver, P.R., Yunger, J.L, \& Perry, D. G. (2003). Gender identity and adjustment in middle childhood. Sex Roles, 49(3.4), 2003.

Cate, R. \& Sugawara, A. I. (1986). Sex role orientation and dimensions of self-esteem among middle adolescents. Sex Roles, 15(3/4), 145-157.

Ceglie, D.D. (2000). Gender identity disorder in young people. Advances in Psychiatric Treatment, 6, 458-466.

Chant, S. \& Craske, N. (2003). Gender in Latin America. New Brunswick, NJ: Rutgers University Press.

Choi, N. \& Fuqua, D. (2003). The structure of the Bem Sex Role Inventory: A summary of 23 validation studies. Educational and Psychological Measurement, 63(5), 872-887.

Cohen, J. (1988). Statistical power analysis for the behavioral sciences. Hillsdale, NJ: Lawrence Erlbaum Associates, Inc., Publishers.

Comas-Diaz, L. (1987). Feminist therapy with Hispanic/Latina women: Myth or reality? Women and Therapy, 6(4), 39-61.

Constantinople, A. (1973). Masculinity-femininity: An exception to a famous dictum? Psychological Bulletin, 80(5), 389-407.

Cook, E.P. (1985). Psychological Androgyny. Elmsford, NY: Pergamon.

Coopersmith, S. (1967). The antecedents of self-esteem. San Francisco: CA. Freeman \& Co.

Corby, B.C., Hodges, E.V.E., \& Perry, D.G. (2007). Gender identity and adjustment in Black, Hispanic, and White preadolescents. Developmental Psychology, 43(1), 261-266. 
Corenblum, B. \& Armstrong, H.D. (2012). Racial-ethnic identity development in children in a racial-ethnic minority group. Canadian Journal of Behavioral Sciences, 44(2),124-137.

Corona, R., Gonzalez, T., Cohen, R., Edwards, C., \& Edmonds, T. (2009). Richmond Latino needs assessment: A community-university partnership to identify health concerns and service needs for Latino youth. Journal of Community Health, 34, 195-201.

D’Andrea, M. \& Daniels, J. (2001). Respectful counseling: An integrative multidimensional model for counselors. In D.B. Pope-Davis \& .L.K Coleman (Eds.), The intersection of race, class, and gender in multicultural counseling (pp. 417-466). Thousand Oaks, CA: Sage Publications, Inc.

Dahlberg L.L., Toal S.B., Swahn M., \& Behrens C.B. (2005). Measuring ViolenceRelated Attitudes, Behaviors, and Influences Among Youths: A Compendium of Assessment Tools. (2nd ed.). Atlanta, GA: Centers for Disease Control and Prevention, National Center for Injury Prevention and Control, 2005.

DiDonato, M.D. \& Berenbaum, S.A. (2011). The benefits and drawbacks of gender typing: How different dimensions are related to psychological adjustment. Archives of Sexual Behavior, 40, 457-463.

Dumont, M. \& Provost, M.A. (1999). Resilience in adolescents: Protective role of social support, coping strategies, self-esteem, and social activities on experience of stress and depression. Journal of Youth and Adolescence, 28(3), 343-363.

Egan, S.K. \& Perry, D.G. (2001). Gender identity: A multidimensional analysis with implications for psychosocial adjustment. Developmental Psychology, 37(4), 451-463.

Erikson, E. (1950). Childhood and Society. New York, NY: Norton \& Company, Inc. 
Fagot, B.I., Leinbach, M.D., \& O’Boyle, C. (1992). Gender labeling, gender stereotyping, and parenting behaviors. Developmental Psychology, 28(2), 225-230.

Fagot, B.I. \& Leinbach, M.D. (1993). Gender-role development in young children: From discrimination to labeling. Developmental Review, 13, 205-224.

Falconier, M.K. (2013). Traditional gender role orientation and dyadic coping in immigrant Latino couples: Effects on couple functioning. Family Relations: Interdisciplinary Journal of Applied Family Studies, 62, 269-283.

Falicov, C.J. (1998). Latino families in therapy: A guide to multicultural practice. New York, NY: The Guilford Press.

Fernandez, J. \& Coello, M.T. (2010). Do the BSRI and PAQ really measure masculinity and femininity? The Spanish Journal of Psychology, 13(2), 1000-1009.

Gagné, P. \& Tewksbury, R. (1998). Conformity pressures and gender resistance among transgendered individuals. Social Problems, 45(1), 81-101.

Gilbert, L.A. (1981). Toward mental health: The benefits of psychological androgyny. Professional Psychology, 12(1), 29-38.

Greenberg, E., Chen, Chen, C., Dmitrieva, J. \& Farruggia, S.P. (2003). Item-wording and the dimensionality of the Rosenberg Self-Esteem Scale: do they matter? Personality and Individual Differences, 35, 1241-1254.

Gorrese, A. \& Ruggieri, R. (2013). Peer attachment and self-esteem: A meta-analytic review. Personality and Individual Differences, 55, 559-568.

Gutmann, M. (1996). The meanings of macho: Being a man in Mexico City. Berkeley, CA: University of California Press. 
Hall, J.A. \& Halberstadt, A.G. (1980). Masculinity and femininity in children:

Development of the Children's personal attributes questionnaire. Developmental Psychology, 16(4), 270-280.

Harter, S. (1985). The self-perception profile for children: Revision of the perceived competence scale for children (Manual). Denver, CO: University of Denver.

Heatherton, T.F. \& Wyland, C.L. (2003). Assessing self-esteem. In S.J. Lopez \& C.R. Snyder (Eds.), Positive Psychology Assessment (pp. 219-233). Washington DC: American Psychological Association.

Hefner, R., Rebecca, M., \& Oleshansky, B. (1975). Development of sex-role transcendence. Human Development, 18, 143-158.

Herrera, C.J., Owens, G.P., \& Mallinckrodt, B. (2013). Traditional machismo and caballerismo as correlates of posttraumatic stress disorder, psychological distress, and relationship satisfaction in Hispanic veterans. Journal of Multicultural Counseling and Development, 41, 21-35.

Hill, K.G., Howell, J.C., Hawkins, J.D., \& Battin-Pearson, S.R. (1999). Childhood risk factors for a adolescent gang membership: Results from the Seattle social development project. Journal of Research in Crime and Delinquency, 36(3), 300- 322.

Holt, C.L. \& Ellis, J.B. (1998). Assessing the current validity of the Bem Sex-Role Inventory. Sex Roles, 39(11/12).

Hosogi, M., Okada, A., Fujii, C., Noguchi, K., \& Watanabe, K. (2012). Importance and usefulness of evaluating self-esteem in children. BioPsychoSocial Medicine, 6:9.

Huang C. \& Dong, N. (2011). Factor structures of the Rosenberg self-esteem scale: A meta-analysis of pattern matrices. European Journal of Psychological Assessment, 28(2), 132-138. 
Ingoldsby, B.B. (1991). The Latin American family: Familism vs. Machismo. Journal of Comparative Family Studies, 22(1), 57-62.

Janis, I.L. \& Field, P.B. (1959). Sex differences and factors related to persuasibility. In C.I. Hovland \& I.L. Janis (Eds.), Personality and persuasibility (pp. 55-68). New Haven, CT: Yale University Press.

Kagan, J. (1964). Acquisition and significance of sex typing and sex-role identity. In M.L. Hoffman \& L. Hoffman (Eds.), Review of child development research (Vol. 1, pp. 137167). New York, NY: Russell Sage Foundation.

Kelly, J.A. \& Worell, J. (1977). New formulations of sex roles and androgyny: A critical review. Journal of Consulting and Clinical Psychology, 45(6), 1101-1115.

Knight, G.P., Losoya, S.H., Cho, Y.I., Chassin, L., Cota-Robles, S., \& Williams, J.L. (2012). Ethnic identity and offending trajectories among Mexican American juvenile offenders: Gang membership and psychosocial maturity. Journal of Research on Adolescence, 22(4), 782-796.

Kohlberg, L. (1966). A cognitive-developmental analysis of children's sex role concepts and attitudes. In E.E. Maccoby (Ed.), The development of sex differences (pp. 82-172). Stanford, CA: Stanford University Press.

Kohlberg, L. (1969). Stage and sequence: The cognitive-developmental approach to socialization. In D.A Goslin (Ed.), Handbook of socialization theory and research (pp. 707-732). Chicago, IL: Rand McNally \& Company.

Lam, C.B., McHale, S.M., \& Updegraff, K.A. (2012). Gender dynamics in Mexican American families: Connecting mothers', fathers', and youths' experiences. Sex Roles, 67, 17-28.

Lamke, L.K. (1982). The impact of sex-role orientation on self-esteem in early adolescence. Child Development, 53(6), 1530-1535. 
Lau, S. (1989). Sex role orientation and domains of self-esteem. Sex Roles, 21(5/6), $415-421$.

Lindsey, L.L. (1997). Gender roles: A sociological perspective (3 ${ }^{\text {rd }}$ ed.). Upper Saddle River, NJ: Prentice-Hall, Inc.

Mann, M., Hosman, C.M.H., Schaalma, H.P., \& de Vries, N.K. (2004). Self-esteem in a broad spectrum approach for mental health promotion. Health Education Research, 19(4), 357372.

Massad, C.M. (1981). Sex role identity and adjustment during adolescence. Child Development, 52, 1290-1298.

Mora, R. (2012). Do it for all your pubic hairs: Latino boys, masculinity, and puberty. Gender \& Society, 26(3), 433-460.

Morales, E. (1996). Gender roles among Latino gay and bisexual men: Implications for family and couple relationships. In J. Laird \& R. J. Green (Eds.), Lesbians and gays in couples and families: A handbook for therapists (pp. 272-297). San Francisco, CA: Jossey-Bass.

Mussen, P. (1969). Early sex-role development. In D.A Goslin (Ed.), Handbook of socialization theory and research (pp. 707-732). Chicago, IL: Rand McNally \& Company.

O'Brien, M. \& Huston, A.C. (1985). Activity level and sex-stereotyped toy choice in toddler boys and girls. The Journal of Genetic Psychology: Research and Theory on Human Development, 146(4), 527-533.

O'Connor, K., Mann, D., \& Bardwick, J. M. (1978). Androgyny and self-esteem in the upper middle class: A replication of Spence. Journal of Consulting and Clinical Psychology, 46, 1168-1169. 
Orth, U. \& Robins, R. (2013). Understanding the link between self-esteem and depression. Current Directions in Psychological Science, 22(6), 455-460.

Parra-Cardona, J. R., Cordova, D., Holtrop, K., Villarruel, F. A., \& Wieling, E. (2008). Shared ancestry, evolving stories: Similar and contrasting life experiences described by foreign born and U.S. born Latino parents. Family Process, 47, $157-172$.

Pedhazur, E.J. \& Tetenbaum, T.J. (1979). Bem sex role inventory: A theoretical and methodological critique. Journal of Personality and Social Psychology, 37, 9961016.

Perry, D.G. \& Pauletti, R.E. (2011). Gender and adolescent development. Journal of Research on Adolescence, 21(1), 61-74.

Phillips, R., Spears, M.R., Montgomery, A.A., Millings, A., Sayal, K., \& Stallard, P. (2013). Could a brief assessment of negative emotions and self-esteem identify adolescents at current and future risk of self-harm in the community? A prospective cohort analysis. BMC Public Health, 13, 604-615.

Phinney, J. (1996). When we talk about American ethnic groups, what do we mean? American Psychologist, 51, 918-927.

Phinney, J.S., Cantu, C.L., \& Kurtz, D.A. (1997). Ethnic and American identity as predictors of self-esteem among African American, Latino and White adolescents. Journal of Youth and Adolescence, 26(2), 165-185.

Pleck, J. (1975). Masculinity-femininity current and alternative paradigms. Sex Roles, $1,161-178$.

Piña-Watson, B., Ojeda, L., Castellon, N.E., \& Dornhecker, M. (2013). Familismo, ethnic identity, and bicultural stress as predictors of Mexican American adolescents' positive psychological functioning. Journal of Latina/o Psychology, 1(4), 204-217. 
Pryor, J. (1994). Self-esteem and attitudes toward gender roles: Contributing factors in adolescents. Australian Journal of Psychology, 46(1), 48-52.

Raffaelli, M. \& Ontai, L.L. (2004). Gender socialization in Latino/a families: Results from two retrospective studies. Sex Roles, 50(5/6), 287-299.

Reed-Sanders, D., Dodder, R. A., \& Webster, L. (2001). The Bem Sex Role Inventory across three cultures. The Journal of Social Psychology, 125)4), 523-525.

Rosenberg, M. (1989). Society and the adolescent self-image (Rev. ed.). Middletown, CT: Wesleyan University Press.

Rosenkrantz, P.S., Vogel, S. R., Bee, H., Broverman, I.K., \& Broverman, D.M. (1968). Sex-role stereotypes and self-concepts in college students. Journal of Consulting and Clinical Psychology, 32, 287-295.

Santiago-Rivera, A.L., Arredondo, P., \& Gallardo-Cooper, M. (2002). Counseling Latinos and la familial: A practical guide. Thousand Oaks, CA: Sage Publications, Inc.

Schmitt, D. P. \& Allik, J. (2005). Simultaneous administration of the Rosenberg SelfEsteem Scale in 53 nations: Exploring the universal and culture-specific features of global self-esteem. Journal of Personality and Social Psychology, 89(4), 623-642.

Sharpe, M.J. \& Heppner, P.P. (1991). Gender role, gender role conflict, and psychological well-being in men. Journal of Counseling Psychology, 38, 323-330.

Shetgiri, R. (2010). Adolescent fighting: Racial/ethnic disparities and the importance of families and schools. Academic Pediatrics, 10(5), 323-329.

Silvern, L.E. \& Ryan, V.L. (1979). Self-rated adjustment and sex-typing on the Bem sexrole inventory: Is masculinity the primary predictor of adjustment? Sex Roles, 5(6), 739-763.

Smoak, N. (2008). Androgyny. In J.A. O'Brien (Ed.), Encyclopedia of Gender and Society (Vol. 2, pp. 34-36). Thousand Oaks, CA: Sage Publications, Inc. 
Spence, J.T., Helmreich, R.L., \& Stapp, J. (1974). The personal attributes questionnaire: A measure of sex roles stereotypes and masculinity-femininty. JSAS: Catalog of Selected Documents in Psychology, 4, 43-44.

Spence, J.T., Helmreich, R.L., \& Stapp, J. (1975). Ratings of self and peers on sex role attributes and their relation to self-esteem and conceptions of masculinity and femininity. Journal of Personality and Social Psychology, 32, 29-39.

Supple, A.J. \& Plunkett, S. W. (2011). Dimensionality and validity of the Rosenberg SelfEsteem Scale for use with Latino adolescents. Hispanic Journal of Behavioral Sciences, 33(1), 39-53.

Taylor, M.C. \& Hall, J.A. (1982). Psychological androgyny: Theories, methods, and conclusions. Psychological Bulletin, 92, 347-366.

Toomey, R.B. \& Umaña-Taylor, A.J. (2012). The role of ethnic identity on self-esteem for ethnic minority youth: A brief review. The Prevention Researcher, 19(2), 8-12.

Twenge, J.M. (1997). Changes in masculine and feminine traits over time: A metaanalysis. Sex Roles, 36(5/6), 305-325.

Twenge, J.M. \& Crocker, J. (2000). Race and self-esteem: Meta-analyses comparing Whites, Blacks, Hispanics, Asians, and American Indians and comment on GrayLittle and Hafdahl (2000). [Abstract]. Psychological Bulletin, 128(3), 371-408.

Umaña-Taylor, A.J. (2004). Ethnic identity and self-esteem: Examining the role of social context. Journal of Adolescence, 27(2), 139-146.

U.S. Census Bureau. (2011, March). Overview of race and Hispanic origin: 2010 census briefs. Retrieved September 26, 2013, from http://.census.gov/prod/cen2010/briefs/c2010br-02.pdf

Vandello, J.A. \& Cohen, D. (1999). Patterns of individualism and collectivism across the United States. Journal of Personality and Social Psychology, 77(2), 279-292. 
Vigil, J.D. (1988). Group processes and street identity: Adolescent Chicano gang members. Ethos, 16, 421-445.

Vigil, J. D. (2003). Urban violence and street gangs. Annual Review of Anthropology, 32, $225-242$.

Weitzman, L.J. (1979). Sex role socialization. Palo Alto, CA: Mayfield Publishing Company.

Whitley, B.E. (1983). Sex role orientation and self-esteem: A critical meta-analytic review. Journal of Personality and Social Psychology, 44(4), 765-778.

World Health Organization. (2000). Preventing suicide: A resource for teachers and other school staff. Retrieved on September 24, 2013, from http://.who.int/mental_health/media/en/62.pdf.

Yager, G.G. \& Baker, S. (1979, September). Thoughts on androgyny for the counseling psychologist. Paper presented at the annual meeting of the American Psychological Association, New York, NY.

Yunger, J.L., Carver, P.R., \& Perry, D. G. (2004). Does gender identity influence children's psychological well-being? Developmental Psychology, 40(4), 572-582.

Zinn, M.B. (1980). Gender and ethnic identity among Chicanos. Frontiers: A Journal of Women Studies, 5(2), 18-24.

Zosuls, K.M., Ruble, D.N., Tamis-LeMonda, C.S., Shrout, P.E., Bornstein, M., \& Greulich, F.K. (2009). The acquisition of gender labels in infancy: Implications for gender-typed play. Developmental Psychology, 45(3), 688-701.

Zosuls, K.M., Miller, C.F., Ruble, D.N., Martin, C.L., \& Fabes, R. A. (2011). Gender development research in Sex Roles: Historical trends and future directions. Sex Roles, 64, 826-842. 


\section{APPENDIX A}

Cover Page of Participant Questionnaire Packet

Youth in Action

2013-2014

ID \#

School Name:

Grade:

Date of Birth:

Age:

Month/ Day/ Year

Today's Date: 


\section{APPENDIX B}

Felt Pressure Scale (Egan \& Perry, 2001)

Your job is to circle how true the statement is for you. You have four choices and you circle the one closest to how true that statement is for you.

1. The boys I know would be upset if I wanted to play with girls' toys.

2. My parents would be upset if they saw me acting like a girl.

3. I think it would be wrong for me to play with girls' toys or do girls' activities.

4. The boys I know wouldn't like it if I wanted to learn an activity that girls usually do.

5. I wouldn't like myself if I heard myself talking or laughing like a girl.

6. I would still like myself if I saw myself acting like a girl.

7. My parents wouldn't like it if I wanted to learn an activity that only girls do.
Not at all true

for me

Not at all true

for me

Not at all true

for me

Not at all true
for me

Not at all true

for me

Not at all true

for me

Not at all true

for me
A little true for me

Pretty true for
me

Very true for me $\begin{array}{ccc}\begin{array}{c}\text { A little true } \\ \text { for me }\end{array} & \text { Pretty true for } & \begin{array}{c}\text { Very true for } \\ \text { me }\end{array}\end{array}$

A little true for me

Pretty true for Very true for me

me $\begin{array}{ccc}\begin{array}{c}\text { A little true } \\ \text { for me }\end{array} & \text { Pretty true for } & \begin{array}{c}\text { Very true for } \\ \text { me }\end{array}\end{array}$

A little true for me
Pretty true for Very true for me
me




\author{
APPENDIX C \\ Gender Contentedness and Gender Typicality Scales (Egan \& Perry, 2001) \\ $*=$ Gender Typicality questions
}

First read the two sentences for each question and decide which of those sentences best describes you. Then circle whether that one sentence is either "Very true for me" or Sort of true for me." There are no right or wrong answers. Remember, only one answer choice should be circled for one sentence within each question.

1. Some boys like being a boy $\quad$ BUT Other boys do not like being a boy.

Very True Sort of Very true Sort of

$\begin{array}{lll}\text { For me true forme true for me } & \text { for me true }\end{array}$

\begin{tabular}{|c|c|c|}
\hline${ }^{*} 2$. Some boys feel that the things they & BUT & Other boys feel that the things they \\
\hline like to do in their spare time are & & like to do in their spare time are \\
\hline similar to what most boys like to & & different from what most boys like \\
\hline do in their spare time & & to do in their spare time. \\
\hline Very True & & Very true \\
\hline true for me & & true for me \\
\hline
\end{tabular}

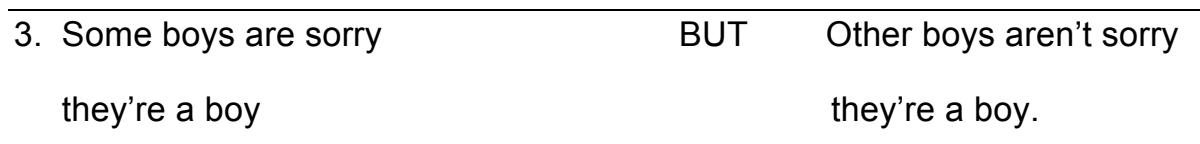

$\begin{array}{llll}\text { Very True } & \text { Sort of } & \text { Very true } & \text { Sort of } \\ \text { For me } & \text { true for me } & \text { for me } & \text { true for me }\end{array}$
*4. Some boys feel they are different BUT Other boys feel they are
from other boys similar to other boys.

$\begin{array}{llll}\text { Very True } & \text { Sort of } & \text { Very true } & \text { Sort of } \\ \text { For me } & \text { true for me } & \text { for me } & \text { true for me }\end{array}$




\begin{tabular}{llll}
\hline $\begin{array}{ll}\text { 5. Some boys are glad they were } \\
\text { a boy }\end{array}$ & BUT & $\begin{array}{l}\text { Other boys wish they had not } \\
\text { been born a boy. }\end{array}$ \\
Very True & Sort of & Very true & Sort of \\
For me & true for me & for me & true for me \\
\hline
\end{tabular}
*6. Some boys have the same feelings BUT Other boys don't have the same that boys have feelings that other boys have.

$\begin{array}{llll}\text { Very True } & \text { Sort of } & \text { Very true } & \text { Sort of } \\ \text { For me } & \text { true for me } & \text { for me } & \text { true for me }\end{array}$

\begin{tabular}{lccc}
\hline $\begin{array}{l}\text { 7. Some boys are unhappy } \\
\text { being a boy }\end{array}$ & BUT & $\begin{array}{l}\text { Other boys are happy } \\
\text { a boy. }\end{array}$ \\
Very True & Sort of & Very true & Sort of \\
For me & true for me & for me & true for me \\
\hline
\end{tabular}

*8. Some boys like to play with the BUT Other boys don't like to play with same toys that other boys do the same toys that other boys do.

$\begin{array}{llll}\text { Very True } & \text { Sort of } & \text { Very true } & \text { Sort of } \\ \text { For me } & \text { true for me } & \text { for me } & \text { true for me }\end{array}$

9. Some boys are glad they'll be $\quad$ BUT Other boys wish they didn't have to be a boy all their life. have to be a boy all their life.

\begin{tabular}{llll} 
Very True & Sort of & Very true & Sort of \\
For me & true for me & for me & true for me \\
\hline
\end{tabular}




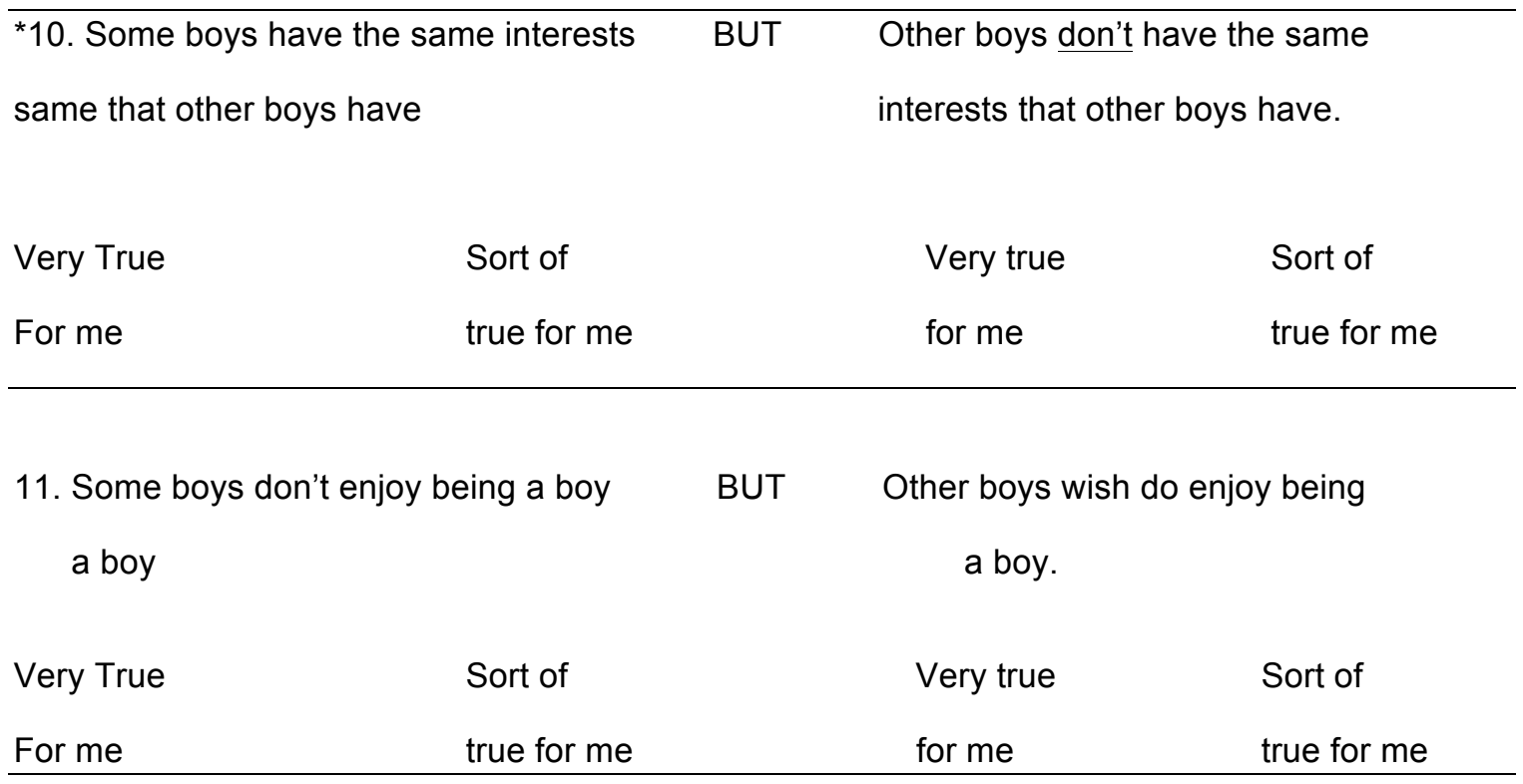




\section{APPENDIX D \\ Rosenberg Self-Esteem Scale (Rosenberg, 1989)}

Below is a list of statements dealing with your general feelings about yourself. If you strongly agree, circle SA. If you agree, circle A. If you disagree, circle D. If you strongly disagree, circle SD.

\begin{tabular}{|c|c|c|c|c|c|}
\hline & & $\begin{array}{c}\text { Strongly } \\
\text { Agree }\end{array}$ & Agree & Disagree & $\begin{array}{l}\text { Strongly } \\
\text { Disagree }\end{array}$ \\
\hline 1. & $\begin{array}{l}\text { I feel that I'm a person of } \\
\text { worth, at least on an equal } \\
\text { plane with others. }\end{array}$ & SA & A & $\mathrm{D}$ & SD \\
\hline 2. & $\begin{array}{l}\text { I feel that I have a number of } \\
\text { good qualities. }\end{array}$ & $\overline{S A}$ & $A$ & $\mathrm{D}$ & SD \\
\hline 3. & $\begin{array}{l}\text { All in all, I am inclined to feel } \\
\text { that I am a failure. }\end{array}$ & SA & $A$ & $\mathrm{D}$ & SD \\
\hline 4. & $\begin{array}{l}\text { I am able to do things as well } \\
\text { as most other people. }\end{array}$ & SA & $A$ & $\mathrm{D}$ & SD \\
\hline 5. & $\begin{array}{l}\text { I feel I do not have much to } \\
\text { be proud of. }\end{array}$ & SA & $A$ & $\mathrm{D}$ & SD \\
\hline 6. & $\begin{array}{l}\text { I take a positive attitude } \\
\text { toward myself. }\end{array}$ & SA & $A$ & $\mathrm{D}$ & SD \\
\hline 7. & $\begin{array}{l}\text { On the whole, I am satisfied } \\
\text { with myself. }\end{array}$ & SA & $A$ & $\mathrm{D}$ & SD \\
\hline 8. & $\begin{array}{l}\text { I wish I could have more } \\
\text { respect for myself. }\end{array}$ & SA & A & $\mathrm{D}$ & SD \\
\hline 9. & $\begin{array}{l}\text { I certainly feel useless at } \\
\text { times. }\end{array}$ & SA & $A$ & $\mathrm{D}$ & SD \\
\hline 10. & $\begin{array}{l}\text { At times I think I am no good } \\
\text { at all. }\end{array}$ & SA & $A$ & $\mathrm{D}$ & SD \\
\hline
\end{tabular}




\section{APPENDIX E \\ Ethnic Identity Teen Conflict Survey (Bosworth \& Espelage, 1995) \\ My Ethnic Identity}

1. My ethnicity is

1. Asian, Asian American

2. Black or African American

3. Hispanic, Latino, Mexican American

4. White, Caucasian, European American

5. American Indian, Native American

6. Mixed; parents are from two different ethnic groups

7. Other (write in):

2. My father's ethnicity is (use numbers above or write in):

3. My mother's ethnicity is (use numbers above or write in):

Circle the one that describes you best for each of the following sentences:

1. I enjoy learning about my own ethnic group, such as its history, traditions, and customs.
Never
Not often
Sometimes
A lot
Always

2. I am accepting of others regardless of their race, culture, or religion.
Never
Not often
Sometimes
A lot
Always

3. I have a strong sense of belonging and attachment to my own ethnic group.
Never
Not often
Sometimes
A lot
Always

4. I would help someone regardless of their race, culture, or religion.
Never
Not often
Sometimes
A lot
Always

5. I am proud to be a member of my racial/ethnic group.
Never
Not often
Sometimes
A lot
Always

6. I can get along well with most people.
Never
Not often
Sometimes
A lot
Always 


\section{APPENDIX F \\ Informed Consent (English and Spanish) \\ INFORMED CONSENT FOR YOUTH TO PARTICIPATE IN YOUTH IN ACTION PROGRAM EVALUATION STUDY}

A program effectiveness study is being conducted with the Youth In Action (YIA) Program by Lisa Sweatt, Ph.D. in the Psychology and Child Development Department at Cal Poly State University, San Luis Obispo. The purpose of this study is to better understand how the YIA Program impacts how you feel and think about yourself and others, and if it has an impact on your behavior. In other words, we want to know more specifically how youth benefit through their participation in the YIA Program.

You are being asked to take part in this study by completing a series of questionnaires at the beginning of your participation in YIA and then again at the end of the YIA Program. Your participation will take approximately one hour of your time on two separate occasions. You will complete these questionnaires at your school site. You will be asked questions about how you feel about yourself, your family, and your friends, behaviors related to your health, your personal strengths, and your beliefs and attitudes about aggression and gangs. Information regarding your educational history and legal history will also be gathered, if applicable. Please be aware that you are not required to participate in this study and you may discontinue your participation at any time without penalty. Your choice to participate or not participate in this study will not positively or negatively affect your participation in the YIA Program.

Your confidentiality will be protected. Youth who choose to participate in the study will be instructed to not write their names on any of the questionnaires and instead will be assigned an identification number. This identification number/name list will only be available to the principle investigator, Dr. Sweatt, and will be kept in a secure, locked cabinet. Confidentiality will only be broken if it is discovered that you may be in danger of being abused or neglected, or you are in danger of hurting oneself or another. If any of these limits to confidentiality are met, the appropriate authorities will be notified immediately for your safety and protection (Child Protective Services and Law Enforcement). Dr. Lisa Sweatt and Mr. Pedro Arroyo are responsible for determining whether or not a child abuse/neglect report needs to be made.

The possible risks associated with your participation in this study are minimal. A YIA staff member and Cal Poly research staff member will be present during the administration of the questionnaires in order to answer any questions you might have. However, if you should become distressed during or after completing the questionnaires, you will be referred to an appropriate YIA staff member and/or school counselor. The information gained through your participation in this study will greatly help in the improvement of the YIA Program, which will ultimately assist other youth and families similar to yours.

If you have questions regarding this study or would like to be informed of the results when the study is completed, please feel free to contact Lisa Sweatt, Ph.D. at 805-756-6123, or Pedro Arroyo, M.A., Coordinator of Youth In Action Program, at 805-769-1000 ext. 30125. If you have any questions or concerns regarding the manner in which the study is conducted, you may contact Dr. Steve Davis, Chair of the Cal Poly Human Subjects Committee, at (805) 756-2754, 
sdavis@calpoly.edu, or Dr. Wendt, Interim Dean of Research, at (805) 756-1508, dwendt@calpoly.edu.

If you agree to voluntarily participate in this research study as described, please indicate your agreement by signing below. Please keep one copy of this form for your reference. Thank you for your participation in this research.

Name of Youth Participant:

Please print name

Signature of Youth Participant

Date

Signature of Researcher

Date

Lisa Sweatt, Ph.D.

Associate Professor

Psychology \& Child Development Department

California Polytechnic State University, San Luis Obispo 


\section{PERMISO DE LOS PADRES PARA LA PARTICIPACIÓN DE JÓVENES}

\section{EN EL STUDIO DE EVALUACION DEL PROGRAMA YOUTH IN ACTION}

Un estudio de la eficacia del programa de Youth In Action (YIA) se está llevando a cabo por la profesora de Psicologia Clinica Lisa Sweatt, Ph.D., del Departamento de Psicologia y Desarrollo Infantil de la Universidad Politécnica Estatal de California en San Luis Obispo ("Psychology and Child Development Department at Cal Poly State University, San Luis Obispo"). El propósito de este estudio es de mejorar nuestro entendimiento de cómo el programa de YIA afecta lo que su hijo siente y piensa de si mismo y de los demás, y si afecta su comportamiento. En otras palabras, queremos saber más especificamente còmo benefician los jóvenes por su participación en el programa de YIA.

Se la estápidiendo a su hijo que participe en este estudio a través de dos cuestionarios: uno al comienzo de la participación de su hijo en el programa de YIA y otro al fin del programa. La participación de los jóvenes tomará aproximadamente una hora en dos ocasiones distintas. Completarán los cuestionarios en su propia escuela. A su hijo se le harán preguntas sobre cómo se siente hacia si mismo, su familia y sus amigos, sobre conductas relacionadas con su salud, sus puntos fuertes personales y sus creencias y actitudes hacia la agresión y las pandillas. Además, se la pedirá información sobre su historial educativo y legal. Por favor tenga en cuenta que ellos no tienen la obligaciòn de participar en este estudio y usted o ellos pueden dejar de participar en cualquier momento sin ninguna consecuencia negativa. La decisión de su hijo de participar o de no participar en este estudio no afectará ni positivamente ni negativamente la participación de su hijo en el programa de YIA.

La confidencialidad de su hijo sera protegida. Los jóvenes que decidan participar en este estudio serán instruidos de no escribir sus nombres en ninguno de los cuestionarios; en vez de esto, se les asignará un número de identificación. La lista de numerous de identificación sólo estará disponible a la investigadora principal, la Dra. Sweatt, y se mantendrá en un gabinete seguro y cerrado con llave. Esta confidencialidad sólo terminará si se descubre que su hijo puede estar en peligro de ser abuado, descuidado o abandonado, o sis su hijo estáem peligro de herirse a si mismo o a otros. Si alguno de estos limites de confidencialidad se llega a cumplir, las autoridades apropriadas serán notifacadas inmediatamente (Servicios de Protección Infantil y la Policia- “Child Protectisve Services" y "Law Enforcement"). La Dra. Lisa Sweatt y el Sr. Pedro Arroyo tiene la responsabilidad de determiner si es necesario hacer un informe de abuso/descuido de un niño.

Los posibles riesgos asociados con la participación de su hijo este estudio son minimos. Un miembro del persona del programa de YIA y un miembro del personal de investigación de Cal Poly esterán presentes durante la adminstración de los cuestionarios para poder contester cualquier pregunta que su hijo tenga. Sin embargo, sis su hijo se trastorna durante o después de completer los cuestionarios, se la haráuna referencia a un miembro del personal del programa de YIA/o a un consejero escolar. La información obtenida a través de su participación y la de su hijo 
en este estudio será de gran ayuda para mejorar el programa de YIA, lo cual aydará a jóvenes y familias similares a la suya.

Si usted o su hijo tiene preguntas acerca de este estudio o si quisiera ser informado de los resultados cuando el estudio termine, por favor no vacile en contactar a Lisa Sweatt, PhD., al (805) 756-6123 o al Sr. Pedro Arroyo, M.A., Coordinator del Programa de Youth In Action al (805) 474-7493. Si usted o su hijo tiene cualquier pregunta o preocupación con respecto a la manera en que el estudio se lleva a cabo, usted puede contactar al Dean Wendt, Interim Dean of Research de Cal Poly, al (805) 756-1508, dwendt@calpoly.edu.

Si está de acuerdo que su hijo participe voluntariamente en este estudio de investigación como se ha descrito, por favor indique su acuerdo firmando abajo. Por favor guarde una copia de este document para su referencia. Gracias por su participación en esta investigació.

Nombre del niño participante en el estudio:

(Favor de escribir su nombre en letra do molde)

Firma del Padre/de la Madre/del Tutor Legal

Fecha

Firma del Padre/de la Madre/del Tutor Legal

Fecha

Lisa Sweatt, Ph.D.

Associate Professor

Psychology \& Child Development Department

California Polytechnic State University, San Luis Obispo 